\title{
Printing Meets Lithography: Soft Approaches to High-Resolution Patterning\#
}

\author{
Bruno Michel ${ }^{\star}$, André Bernard ${ }^{a}$, Alexander Bietsch, Emmanuel Delamarche, Mattias Geissler, \\ David Juncker, Hannes Kind ${ }^{\mathrm{b}}$, Jean-Philippe Renault ${ }^{\mathrm{c}}$, Hugo Rothuizen, Heinz Schmid, Patrick \\ Schmidt-Winkel ${ }^{d}$, Richard Stutz, and Heiko Wolf
}

\begin{abstract}
We are developing a high-resolution printing technique based on transferring a pattern from an elastomeric stamp to a solid substrate by conformal contact. This is an attempt to enhance the accuracy of classical printing to a precision comparable with optical lithography, creating a low-cost, large-area, high-resolution patterning process. First, we introduce the components of this technique, called soft lithography, and review its evolution. Topics described in detail are the stamp material, stamp architecture, pattern design rules, and printing tools. The accuracy of the prints made by thin patterned elastomeric layers supported on a stiff and flexible backplane is then assessed, and defects are characterized using a new electrical metrology approach. This is followed by a discussion of various printing processes used in our laboratory: (1) thiol printing for high-resolution patterns of noble metals that may also be used as sacrificial masks; (2) confined contact processing with liquids in cavities or channels to chemically convert a substrate or deposit layers of materials or biomolecules; (3) printing of catalysts to mediate patterned deposition of metals; and (4) structured, light-guiding stamps for transferring high-resolution patterns into photoresists. Finally, we compare classical and high-resolution printing approaches, and describe their potential for emerging micro- and nanoscale patterning technologies.
\end{abstract}

Keywords: Biopattern · Elastomeric · Electroless · Flexography · High resolution · Light stamp · Microcontact print $\cdot$ Microfluidic $\cdot$ Mold $\cdot$ Nanopattern $\cdot$ PDMS $\cdot$ Soft lithography

${ }^{{ }^{*} \text { Correspondence: }}$ Dr. B. Michel

IBM Research

Zurich Research Laboratory

Säumerstr. 4

$\mathrm{CH}-8803$ Rüschlikon

Tel.: +4117248648

Fax: +4117248966 or 8952

E-Mail: bmi@zurich.ibm.com

http://www.zurich.ibm.com/st/microcontact/ index.html

aNow at indigon $\mathrm{GmbH}$

Albrechtstrasse 9, D-72072 Tübingen, Germany

E-Mail: a.bernard@indigon.de

${ }^{b}$ Now with the Department of Chemistry

University of California, Berkeley, CA 94720, USA

E-Mail: kind@uclink4.berkeley.edu

cNow with the Commissariat à l'Energie Atomique

F-91191 Gif sur Yvette, France

E-Mail: jrenault@drecam.cea.fr

dEPCOS OHG

Ceramic Components Division

Corporate Development (GEA)

Siemensstr. 43

8530 Deutschlandsberg, Austria

E-Mail: patrick.schmidt-winkel@epcos.com

\#Copyright 2001 by International Business

Machines Corporation; reprinted with permission from the IBM Journal of Research and Develop-

ment, vol. 45, no. 5, pp. 697-719 (September 2001).

\section{Introduction}

Printing is one of the most significant technological developments in human history: It created the capability to distribute ideas and ensure their survival over generations. It is possible to trace the origins of printing back to seals used to 'sign' official documents as early as 255 BC. In 1232, movable metal characters were first used in Korea [1] and, 200 years later, the German Johannes Gutenberg reinvented and spread this technique throughout Europe.

Five major printing processes exist today [2][3] that entail the contact transfer of a pattern: relief, intaglio, lithography, screen, and electrophotography (xerography). Relief printing (Fig. 1a) includes letterpress printing, flexographic printing, and other processes of transferring an image from a raised surface. Letterpress printing is being replaced in many areas by flexography, a rotary relief printing process in which the image carrier is an elastic rubber plate (stamp) with raised image areas that is mounted or cured onto a steel or polymer backplane to provide the lateral stability. Intaglio printing or gravure (Fig. 1b) is the inverse process of relief printing - an intaglio image is transferred from a sunken surface. Lithography uses a chemically patterned flat surface with areas that accept ink and areas that repel ink (Fig. 1c). The original lithographic process provided the name for both today's paper-printing technology and the optical lithographies used in the semiconductor industry. Current printing processes are no longer planographic and performed with a platen press, but make use of the high-throughput capabilities of cylindrical rotary presses. Screen or stencil printing (Fig. 1d) transfers an image by passing ink through openings in a stencil that has been applied to a screen substrate. Offset printing uses a soft planar intermediate medium to improve the transfer quality from the master to the substrate. It can be used in conjunction with relief, intaglio, 
and lithographic printing, and is widely used for all forms of paper publications. Electrophotography creates an image by selectively discharging areas of a photoconductor drum to directly transfer a toner powder (Fig. 1c). Finally, a process that does not entail the contact of a stamp with a substrate but has become important for pattern generation and replication is ink-jet printing (Fig. 1e) [3].

Printing processes were originally developed for the exchange and storage of information adapted to human vision. This field of application requires pattern and overlay accuracies down to $20 \mu \mathrm{m}$ for highquality reproduction. In a few cases, printing processes have been used for technological patterning: Gravure offset printing was used to make $50-\mu \mathrm{m}$ wide conductor lines on ceramic substrates [4][5] and to pattern thin-film transistors for low-cost displays [6]. Offset printing was used for the fabrication of capacitors [7] and printed and plated metal lines as narrow as $25 \mu \mathrm{m}$ [8]. Electrophotography was used to pattern transistors [9] and conductors or dielectric materials [10]. In display-color-filter patterning and patterning of organic lightemitting diode (OLED) displays, limited edge resolution, thickness homogeneity, and overlay problems restrict the printing approaches to low-resolution applications [11]. Finally, printed circuit boards and integrated circuit packaging are popular applications of screen printing in the electronics industry. In general, tooling and process limitations have precluded printing structures smaller than $20 \mu \mathrm{m}$ in the electronic industry, and it seems that - despite the large pressure on cost - the volume of these applications was too small to constitute a driving force for the development of more accurate printing tools.

Resist patterns for manufacturing integrated circuits were generated - in the initial phase - using optical contact masks. 'Hard' contact lithographies [12][13] were abandoned for high-resolution patterning because the accumulation of defects caused by the physical contact between masks and wafer limited multiple reuse of the masks. The economic importance of semiconductor manufacturing has attracted huge investments to optical lithographic processes. The spectacular progress in chip manufacturing has been driven by equally spectacular progress in optical lithography. As a consequence, most of the high-resolution patterning performed today is done with step-and-repeat projection lithography [14][15].

Printing approaches regained attention when, in 1993, Kumar and Whitesides discovered that a polymer inked with an alkane-

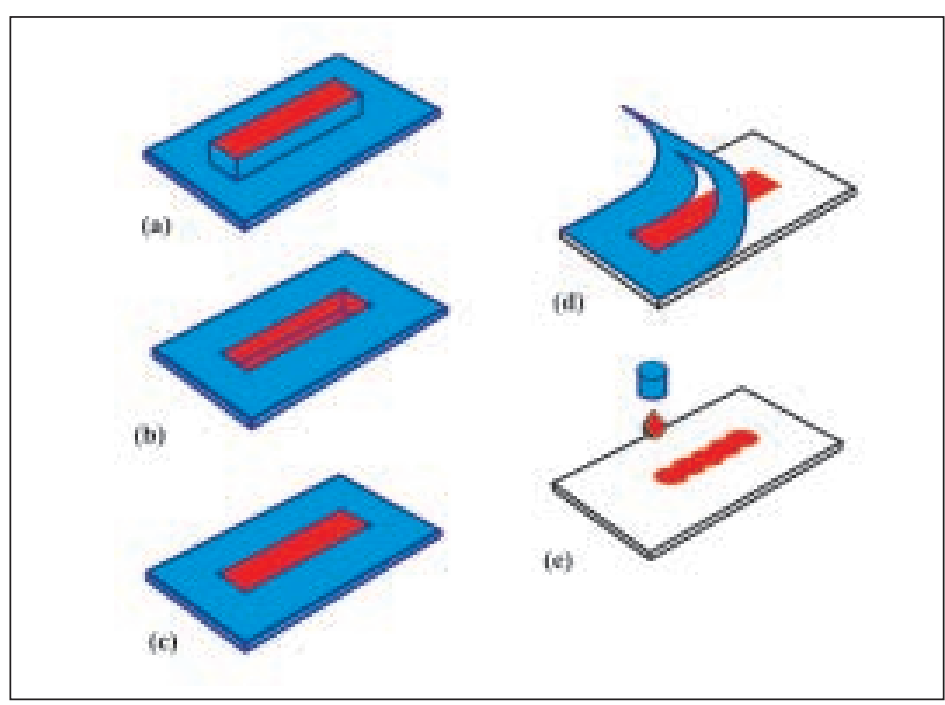

Fig. 1. Diagram of the patterning elements (blue) with the ink (red) of major print techniques: (a) Relief printing, (b) intaglio printing, (c) lithographic printing and electrophotographic (xerographic) printing, (d) screen or stencil printing, and (e) ink-jet printing. Red areas depict how the ink (red) is accepted on the stamp [blue, (a-c)] and applied to the substrate [white, $(d, e)]$. Transfer of the ink from the pattern to the target substrate via a rubber plate (offset printing) is possible with most methods shown here.

thiol and brought into contact with a goldcoated surface can form a monolayer of these molecules in the areas of contact [16][17]. This flexographic printing process, called microcontact printing, prints directly off a patterned elastomeric stamp. The revolutionary new concept of this process is that it transfers only a molecular monolayer of ink to a surface. The latter renders it insensitive to detrimental wetting and squeezing effects of macroscopic amounts of viscous ink between stamp and substrate, and allows the size of printed patterns to be reduced dramatically. Microcontact printing gave rise to the development of a set of related patterning approaches now summarized by the term soft lithography. The fundamental characteristic of soft lithography is the formation of a contact on the molecular scale between the stamp and the substrate.

Given the higher economic potential, we shifted our strategy of nano-patterning self-assembled monolayers from using scanning tunneling microscopy (STM) [18] to microcontact printing. This effort led to an earlier contribution to the IBM Journal of Research and Development entitled 'Lithography beyond light: Microcontact printing with monolayer resists' [19]. Soft lithography has spread so rapidly that we can no longer give a complete overview of the entire field in the context of this paper, but refer to a recent review [20, and references therein] and other publications
[21-28] that document the development of the field. Nor can we cover embossing, which displaces or molds a layer of material and which is now being developed as nano-imprint lithography [29-35], and molding against elastomeric masters [36-41]. Instead, we focus on high-resolution printing, accuracy aspects, and alternative replication schemes of soft lithography.

\section{Conformal Contact}

All printing processes can be logically divided into two steps: The first is to define an accurate pattern, and the second is to bring it close enough to the substrate so that the desired process (ink transfer, chemical reaction, sealing, or optical exposure) can be executed. In the case of letterpress, intaglio, and electrographic printing, paper and plastic adapt to a hard printing plate and thus fulfill the second function. To improve print reliability and to extend printing to hard substrates such as metals, ceramics, glass, and silicon, 'offset' presses use a soft rubber transfer layer for the adaptive function. Flexography and soft lithography combine both functions in one physical component: A patterned elastomeric stamp mediates intimate contact between the ink on the elastomeric stamp and the substrate.

The definition of this intimate or 'conformal' contact in high-resolution printing 
goes beyond contact between the asperities of two flat, hard surfaces (i.e. when a glass mask is pressed onto a resist surface). Conformal contact comprises (1) the macroscopic adaptation to the overall shape of the substrate and (2) the microscopic adaptation of a soft polymer layer to a rough surface, leading to an intimate contact without voids (Fig. 2). Adhesion forces mediate this elastic adaptation, and even without the application of external pressure, an elastomer can spontaneously compensate for some degree of substrate roughness, depending on the material properties (Fig. 2c) [42]. The stamps we use are composed of a patterned elastomeric layer (blue layer in Fig. 2) attached to a thin bendable layer of metal, glass, or polymer (dark layer in Fig. 2). In this 'hybrid' stamp, the conformal properties of a thin layer of supporting metal or glass and those of the elastomer are complementary. The elastomer compensates for local surface-roughness amplitudes of up to $1 \mu \mathrm{m}$ (Fig. 2c), whereas long-range warp (wavelengths greater than $100 \mu \mathrm{m}$ ) is compensated by the flexibility of the backplane (Fig. 2b). Conformal contact benefits from a low Young's modulus and moderate, yet sufficient, work of adhesion. The stability of small patterns, however, requires a stiff material - an inherent contradiction.

Moreover, reliable and repeatable conformal contact and defect-free separation demand the following three features: (1) a relatively low and defined Young's modulus and high toughness to avoid local overload and defects caused by brittle failure of vulnerable features; (2) a rubber elastic behavior to allow stamps to recover their original shape even after having undergone significant strain (> 25\%); and (3) a low work of adhesion to allow the stamp to separate from the substrate at low force and to prevent the sticking of particles to the substrate. All of these requirements presuppose a sound understanding of the mechanics of stamps in order to optimize the system for soft-lithography applications.

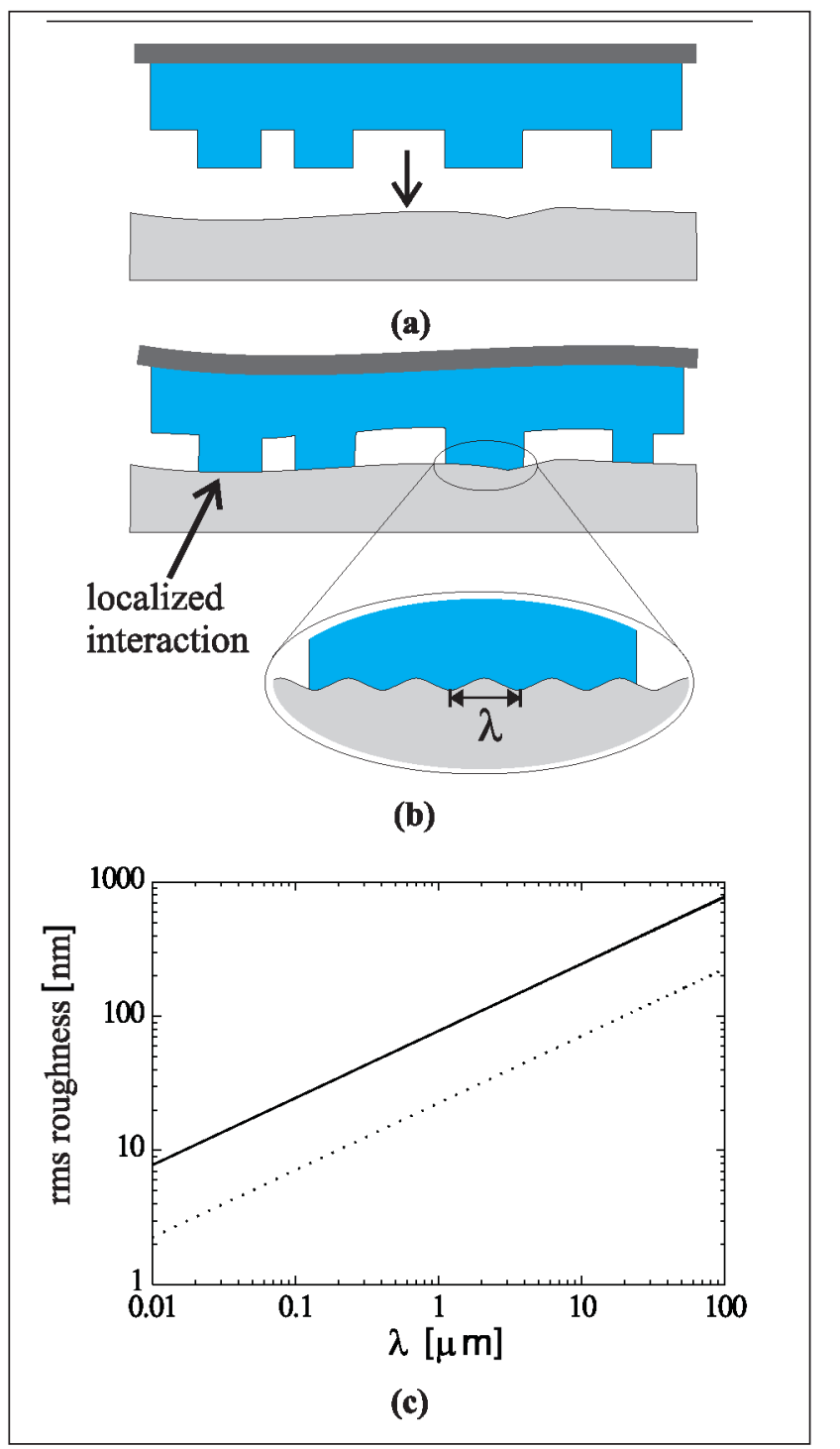

\section{Microcontact Printing of Thiols: The Soft-Lithography Model System}

Microcontact printing of alkanethiols on gold was the first representative of softlithography processes. We use this model system and describe its technical elements to provide a solid starting point for further discussions of important aspects of printing. As shown in Fig. 3, soft lithography relies on $(1,2)$ replication of a patterned elastomeric stamp from a master to form an elastic stamp (3) that can be inked with a monolayer-forming ink $(4,7)$ using either wet inking (4) or contact inking (5). The inked stamp is then used to print (6) a pattern that selectively protects the noble-metal substrate during the subsequent etch (8).

\section{(1) Master}

Both printing and soft lithography are techniques based on contact and pattern replication that rely on onefold magnification $(1 \times)$ masks. This renders mask or master fabrication even more challenging than the fabrication of $4 \times$ to $5 \times$ masks for projection lithography. The master we use for soft lithography is a structured silicon or resist surface with a vertical inverse of the desired pattern. Masters with structures larger than $1 \mu \mathrm{m}$ can be fabricated using photolithography on silicon wafers, whereas highresolution masters require e-beam patterning and reactive ion etching of a silicon-oninsulator (SOI) wafer (Fig. 3b). Critical features are definition of smooth bottom surfaces and smooth vertical side walls (no under-etch) as well as coating of the final mold with a fluorinated separation layer.

\section{(2) Elastomer}

Stamps are created by pouring liquid poly(dimethylsiloxane) (PDMS) prepolymers on the master (1) and curing them at temperatures between $20^{\circ} \mathrm{C}$ and $80^{\circ} \mathrm{C}$ for up to $48 \mathrm{~h}$. Stamps used for low-resolution soft lithography are usually made of a commercial siloxane elastomer Sylgard ${ }^{\circledR} 184$ (Dow Corning) with a modulus of $3 \mathrm{MPa}$. Accurate replication of features smaller than $500 \mathrm{~nm}$ required the formulation of harder stamp materials [43].
Fig. 2. Conformal contact between a hybrid stamp and a hard substrate. (a) Stamp composed of a patterned elastomer and a flexible backplane adapts its protruding zones to (b) the macroscopically uneven substrate and (b, inset) its microscopic roughness, whereas recessed zones do not touch the substrate. (c) Dependence of maximal roughness amplitude for spontaneous formation of conformal contact on a substrate with sinusoidal roughness of wavelength $(\lambda)$ for a stamp with a Young's modulus of $2.5 \mathrm{MPa}$ and a work of adhesion of $0.1 \mathrm{~J} / \mathrm{m}^{2}$ (Sylgard 184, solid curve) and for a stamp with a modulus of $9 \mathrm{MPa}$ and a work of adhesion of $0.03 \mathrm{~J} / \mathrm{m}^{2}$ (dotted curve). 


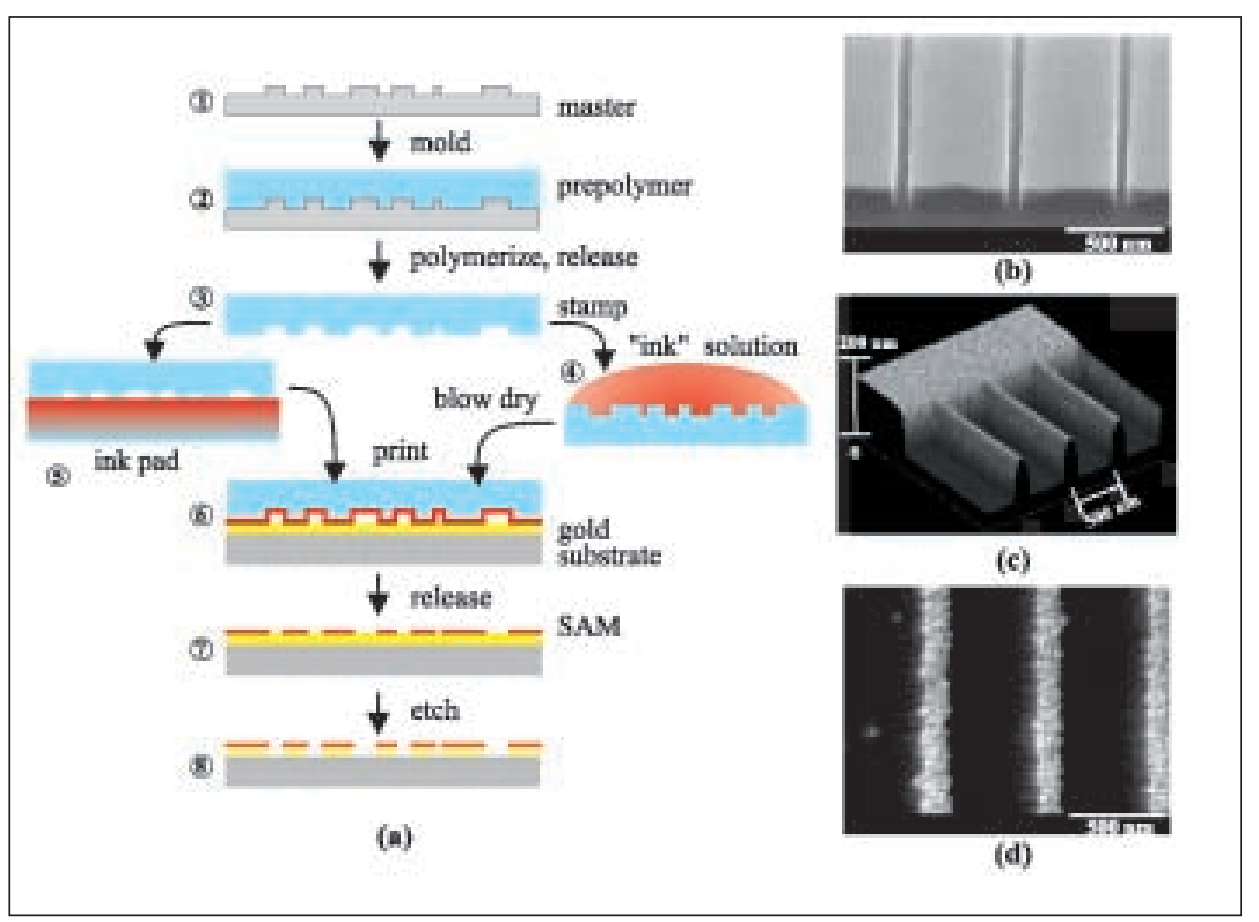

\section{(3) Stamp}

Stability and integrity of topographic structures on stamps were investigated by atomic force microscopy (AFM) after demolding and again after several inking and printing cycles (Fig. 3c). The polymeric surface of the stamp is well suited for microcontact printing of alkanethiols on gold, but other types of inks (biological molecules, catalysts) may require a chemical treatment of the stamp surface. Thermal and chemical shrinkage of the polymer affects the absolute accuracy of molded stamps, but these effects are predictable and can be compensated in the design of the master.

\section{(4) Resist-Forming Ink}

Alkanethiols self-assemble on noblemetal surfaces such as $\mathrm{Au}, \mathrm{Ag}$, and $\mathrm{Cu}$ to form dense, ordered monolayers. These monolayers allow control over wettability, adhesion, chemical reactivity, electrical conduction, and mass transport to the underlying metal [44][45]. The latter property, combined with reduced chemical reactivity, is particularly relevant for lithographic applications for which selective dissolution of the substrate is sought [46]. Accurate reproduction of small patterns (Fig. 4) can be compromised by the diffusion of ink molecules away from the zones of contact. The formation of a defect-free resist requires time and enough reactants to form a monolayer, but this also provides an opportunity for the thiol molecules to diffuse. In fact, the width of the diffusion zone is scaled with the mobility of the molecules:
Use of linear alkanethiols with increasing molecular weight from $158 \mathrm{~g} \mathrm{~mol}^{-1}$ (dodecanethiol, DDT) to $258 \mathrm{~g} \mathrm{~mol}^{-1}$ (hexadecanethiol, HDT), and up to $314 \mathrm{~g} \mathrm{~mol}^{-1}$ (eicosanethiol, ECT) decreased both the vapor-phase transport and the surface diffusion of the ink during printing (Fig. 4b). weight thiols) allows the surface diffusion zone to be reduced to values of less than $100 \mathrm{~nm}$ for immersion inking of the stamp and to values of less than $50 \mathrm{~nm}$ for contact inking of the stamp (Fig. 4a and 4c). ECT offered the best compromise between limited diffusion during printing and good protection of the gold against the cyanide $/ \mathrm{O}_{2}$ etch. Longer alkanethiols tend to form more disordered monolayers on gold and, in addition to their limited solubility in ethanol, tend to crystallize at the surface of PDMS stamps.

\section{(5) Inking Methods}

Immersion inking was done by placing a drop of ink solution onto a stamp for a duration of $30 \mathrm{~s}$. The ink solution was then removed under a stream of nitrogen, leaving a reproducible amount of ink on and in the stamp. This method allowed control only over the average amount of ink transferred [45]. Contact inking (Fig. 3a, step 5) selectively helps direct the ink to where it is needed on the stamp [47]. The degree of comes less dependent on the geometry of the pattern, and diffusion of the thiols during printing is minimized. The transfer of ink is mediated by a PDMS ink pad pre-imECT (purified by removing low-molecularcompletion of the printed monolayer be-
Fig. 3. Soft-lithography components. (a) Diagram of process: A prepolymer (2) covering the master (1) is cured by heat or light, and demolded to form an elastomeric stamp (3). The stamp is inked by immersion (4) or contacted with an ink pad (5), and printed onto the substrate (6), forming a self-assembled monolayer (SAM). The ink pattern (7) is then transferred into the substrate by a selective etch (8). (b) Scanning electron microscopy (SEM) micrographs of the master, (c) image of the stamp, and (d) SEM micrograph of a printed and etched pattern. pregnated with thiols; this also prevents deformation of high-resolution patterns on stamps by capillary force. Control over the amount of ink transferred was possible by changing the concentration of the thiol solution used for preparing the ink pad. Fig. $4 \mathrm{~d}$ shows how both the number of defects and the apparent width of the etched pattern depended on the ink concentration. In this example, best accuracy (ink diffusion less than $2 \times 40 \mathrm{~nm}$ ) and lowest defect counts $(<2 \%)$ were achieved for a $0.1 \mathrm{mM}$ solution of ECT [47].

\section{(6) Printing}

Contrast was further optimized by varying the printing time (Fig. 4e). Here, the ink diffusion remained below $50 \mathrm{~nm}$ for inking times greater than $20 \mathrm{~s}$, and defect counts were less than $2 \%$ for printing times greater than $20 \mathrm{~s}$. The 'process window' in terms of concentration and printing time for very small patterns $(<100 \mathrm{~nm})$ was very narrow. For larger patterns, defect counts can be reduced by tolerating a predictable amount of pattern widening. The most challenging task in this context was to print small features or voids with high accuracy and simultaneously to print large areas with low defect counts (Fig. 5). Exploratory printing was done by placing the stamps on gold substrates for a well-defined duration with no external load. The work of adhesion of the siloxane stamp with the gold substrate mediated spontaneous propagation of the contact front from a place of initial contact over the entire area. Stamps can be used many times for inking and printing. 


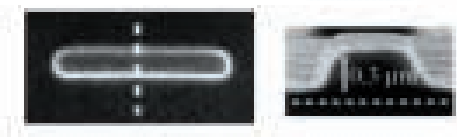

$$
\overline{2 \mu \mathrm{m}} \text { (a) }
$$

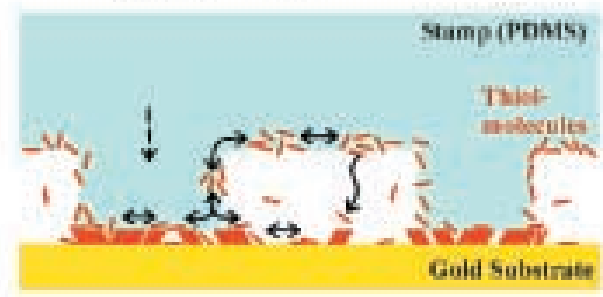

(b)

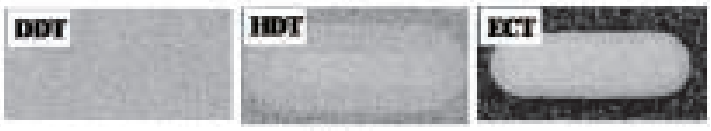

(c)

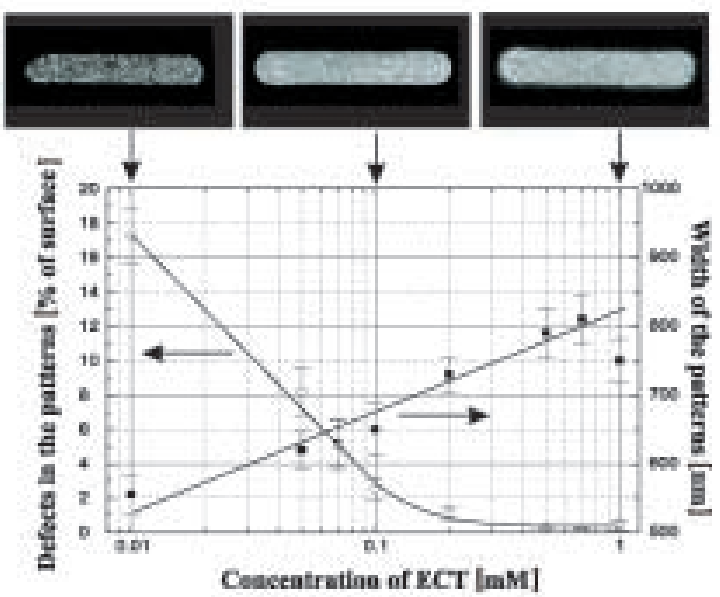

(d)

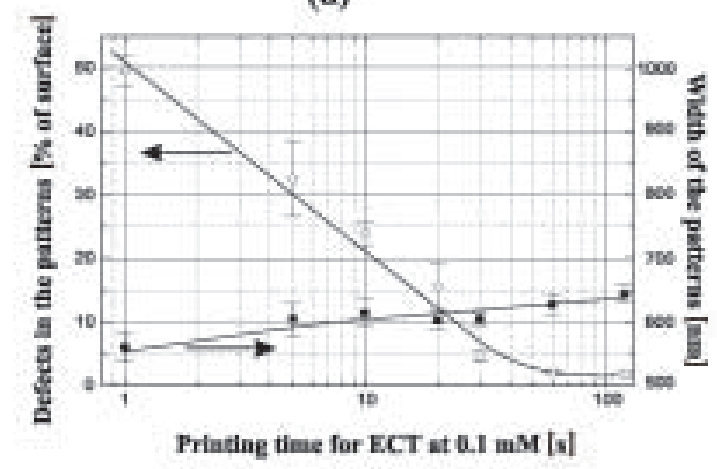

(e)
Fig. 4. Contrast optimization of printed and etched gold structures. (a) SEM image of a $0.6-\mu \mathrm{m} \times 3.0-\mu \mathrm{m}$ feature of the stamp. (b) Scheme showing diffusion paths of molecular ink during printing. (c) Patterns replicated using immersion inking in dodecanethiol (DDT, no contrast), hexadecanethiol (HDT, > 500-nm ink diffusion), and eicosanethiol (ECT, 100-nm ink diffusion). (d) Pattern fidelity (defects and pattern width) as a function of ink (ECT) concentration used for impregnation of the ink pad and (e) as a function of the duration of the print.
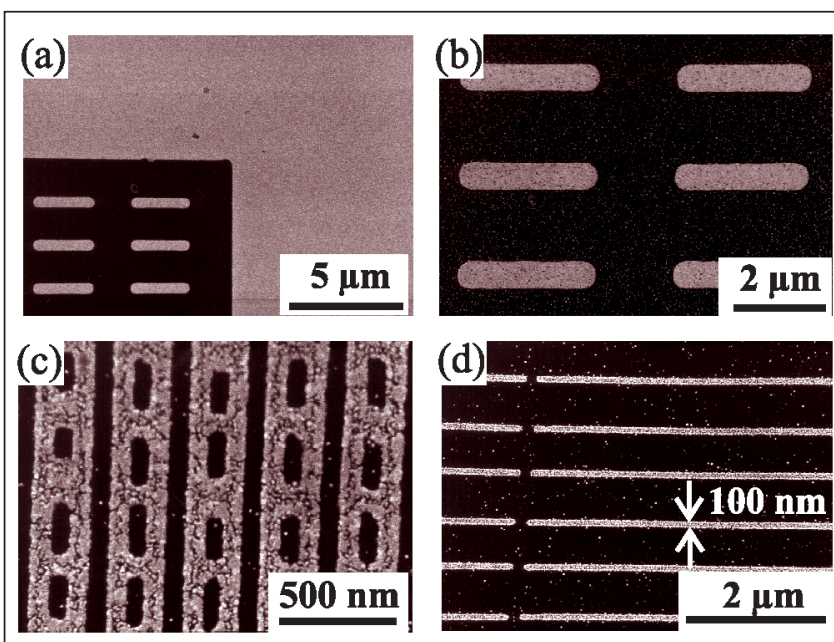

(d)

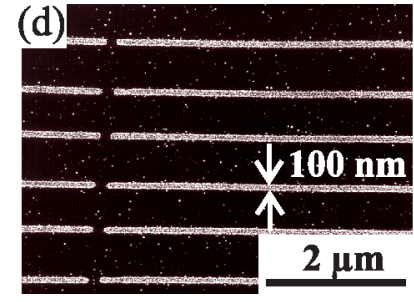

Fig. 5. SEM images of gold patterns produced by contact inking, printing, and etching that are difficult to produce using immersion inking because of (a) simultaneous printing of large areas and small, sparse features; (b) printing of small features using a diffusive and volatile ink; (c) accurate printing of small voids; and (d) formation of 100-nm Au lines. Reprinted with permission from [47]. Copyright 1999 American Chemical Society.

$(7,8)$ Self-Assembled Monolayer as Resist for Wet Etching

A printed pattern of alkanethiols on gold can be visualized by condensation of water droplets, AFM, or SEM [48][49]. Self-assembled monolayers (SAMs) can be used for patterning polymers using wettability, for example, or to control the access of ions (e.g. cyanide) to the underlying gold substrate and thus to allow the selective etching of gold [19][50]. In the latter process, the inherent cooperative ordering of molecules in SAMs can reduce etch defects to very low levels [51].
Microcontact printing can be used to reproduce high-resolution patterns in gold, silver or copper. These can then be used to carry electrical currents or act as secondary etch masks for certain chemical processes and for shallow reactive ion etches. The smallest printable patterns of printed thiols depend on the pattern definition on a stamp, the amount of ink applied to the stamp, the printing force, the printing duration, the etch system, the shape of the structures, and the 'fill' factor of the pattern. In recent experiments we have reproduced 100-nm wide lines and dots. For smaller feature sizes, the granularity of the gold substrate limits the edge resolution to the size of gold grains $(15-30 \mathrm{~nm})$, which are typically protected or completely dissolved (suggesting that the $\mathrm{CN} / \mathrm{O}_{2}$ etch is very sensitive to grain boundaries). Higher printing accuracies can be achieved by applications discussed below using nondiffusive inks (macromolecules) or the confinement of light. Patterning of semiconductors requires use of a sacrificial gold mask on standard resist [52][53], since otherwise the incompatibility of gold with semiconductor processes will allow only special- 
ized-niche applications for microcontact printing of alkanethiols such as patterning of diffractive optical elements.

\section{Evolution of High-Resolution Printing Technology}

Printed thiols on gold can be used as a resist in a subsequent etch process. Important aspects of this model system were the contrast as a function of ink chemistry, the inking method, and printing and etching duration. Similar contrast optimization may be needed for other soft-lithography pattern-replication schemes (see Section 5). Here, we focus on the patterning issues that are crucial to manufacturing: resolution, design rules, accuracy, registration, and yield. We explain how these issues can be addressed by stamp fabrication, printing tool, and printed pattern metrology.

\subsection{Stamp Fabrication}

One of our primary goals was to improve the minimum achievable feature size, or critical dimension (CD). In the past, the $\mathrm{CD}$ of soft lithography was limited by the choice of commercial siloxane with a Young's modulus of $3 \mathrm{MPa}$ as stamp material. This material proved to be too soft to define features smaller than $500 \mathrm{~nm}$ (Fig. 6). Harder stamp materials had to be developed to allow printing with CDs below $100 \mathrm{~nm}$.

Polymer models predicted an inverse dependence of Young's modulus on the molecular mass between crosslinks and a dependence on the number of chains linked at one site, the so-called junction functionality. The toughness, or strain at break, of the materials can be increased by using a bimodal polymer having two populations of chain lengths or by using organic or inorganic fillers. Using these concepts, we were able to formulate stamp materials with a Young's modulus of 9.7 MPa and sufficient toughness for large-area, high-resolution printing applications with feature sizes as small as 80 nm, see Fig. 6b [43]. Currently, the smallest size moldable with high aspect

Fig. 7. Examples of layered hybrid stamps. (a) Scheme of trilayer stamp (hard backplane, elastomeric cushion, hard polymer) showing improved adaptation to an uneven substrate. (b) Trilayer stamp with 270-nm features. (c) Bilayer stamp with $5-\mu \mathrm{m}$ features on a $125-\mathrm{mm}$ glass plate. (d) Example of a two-layer, thinfilm stamp composed of a 100- $\mathrm{mm}$ glass backplane and a $30-\mu m$ polymer film with 270-nm features. Reprinted with permission from [43]. Copyright 2000 American Chemical Society.

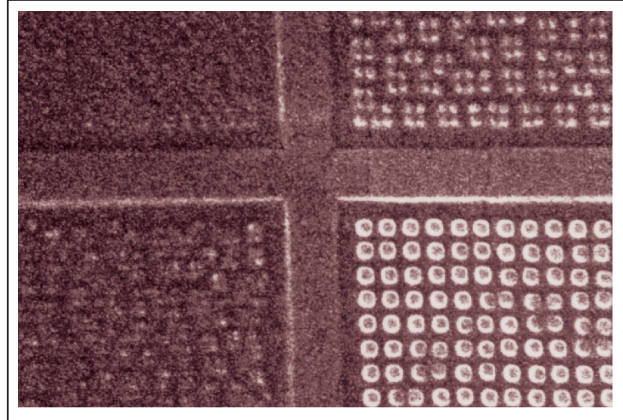

(a)

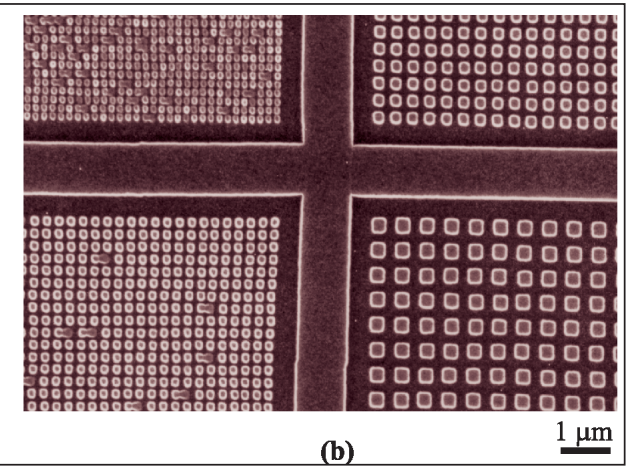

(b)

Fig. 6. Comparison of high-resolution pattern replication by (a) Sylgard 184 with a Young's modulus of $3 \mathrm{MPa}$ and (b) a material with a Young's modulus of 9.7 MPa from a 100-nm deep master. Square posts of $250 \mathrm{~nm} \times 250 \mathrm{~nm}$ (lower right quadrant) are rounded and unstable in the Sylgard 184, whereas the hard material replicates structures down to $80 \mathrm{~nm}$ (upper left quadrant). The SEM images were acquired after coating molded PDMS stamps with a thin layer of gold. Reprinted with permission from [43]. Copyright 2000 American Chemical Society.

ratio is $50 \mathrm{~nm}$. Future materials may require that the amount of unbound chains in the polymer matrix (extractables) be reduced, and that the control over their refractive index as well as over the chemical properties and work of adhesion of the surface be improved. In the future, the accessibility of novel, low-shrinkage and highly purified polymers for stamp fabrication based either on thermocure or ultraviolet cure protocols will be one of the driving forces for improvement of soft lithography.

The high-resolution features defined in the polymer must be integrated into a stamp architecture that allows both high placement accuracy and vertical conformability. 'Hybrid' stamps consisting of a laterally

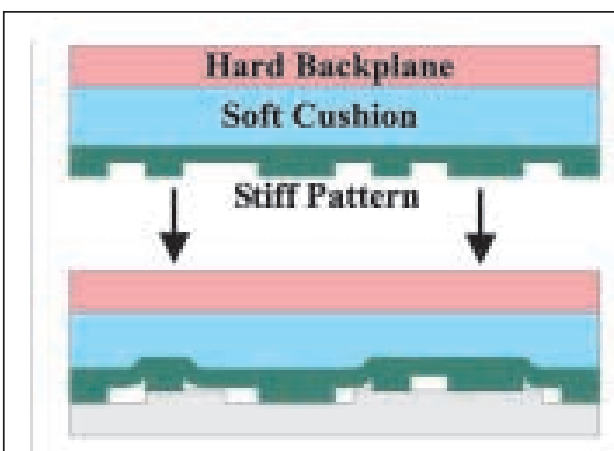

(a)

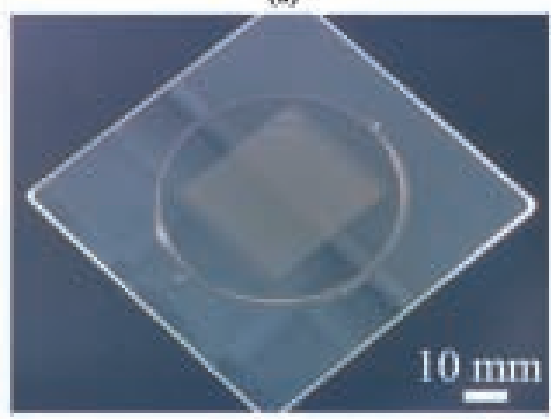

(c) rigid supporting backplane and a thin patterned polymer layer combine both requirements. The polymer layer can be split into a harder layer carrying the pattern and a softer layer for improved conformability (Fig. 7a) [43]. Such a lithographic stamp is fabricated by curing the prepolymer in a well-calibrated gap between the supporting, laterally rigid backplane and a master that defines the pattern. Polymer layers of $200 \mu \mathrm{m}$ or thinner are also beneficial to avoid sagging of large recessed areas. A further design consideration is the necessity to precompensate for isotropic distortions induced by thermal curing, since these have a significant effect on long-range placement accuracy.

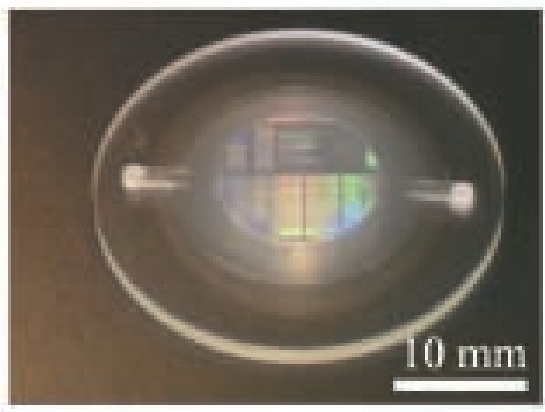

(b)

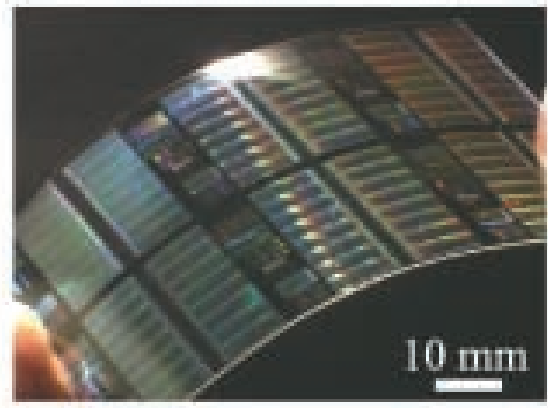

(d) 
The three-dimensional pattern on the stamp must be designed to be compatible with the forces involved in the printing process. Voids of low aspect ratio (the height of features divided by their lateral dimension <0.2) are susceptible to sagging, whereas features of high aspect ratio $(>2)$ exhibit lateral instabilities [54]. Normal pressure is applied to initiate and control conformal contact, but excessive pressures cause patterns to collapse. Model calculations predict the degree of deformation (Fig. 8a) and the critical pressure of the onset of collapse (Fig. 8b) [42][55]. Collapse occurs when the recessed areas of the pattern make contact with the substrate, an effect that can be monitored through a transparent stamp (Fig. 8c) and results in printing on undesired areas. The conformability (i.e. the ratio of Young's modulus divided by the work of adhesion $(E / \omega)$ of the material) was found to be a measure of the spontaneous occurrence of conformal contact as well as of the tendency for pattern collapse to propagate. Interestingly, smaller structures with the same fill factor are more stable against normal pressure (Fig. 8b) but also more susceptible to spreading collapse. In general, large recessed areas have to be avoided, and collapse barriers or frames around critical pattern regions may help prevent the onset and propagation of collapse. Thin layers of polymers on a rigid carrier are less susceptible to collapse because nonprinting areas do not sag and the overall deformation of a thin layer is smaller.

The most challenging stamp designs are those with a broad dynamic range of pattern sizes, i.e. the ratio between the smallest printed feature and the largest unprinted area. This is because the smallest feature determines the typical depth of patterns due to the limited aspect ratio of the protrusions [54]. This pattern depth imposes a low aspect ratio on large recessed zones, which are thus prone to collapse. Complex masters created in more than one lithographic step [56] can handle broader dynamic ranges of patterns but are more expensive and difficult to make.

\subsection{Printing Tools}

The main function of a printing tool is to establish the contact and facilitate the release of a stamp from a substrate with precise control over the printing time, the mechanical forces acting, and the placement of the stamp on the substrate. Other requirements such as inking and cleaning procedures within the printing tool depend on the specific application. In the course of developing the tool and stamp, we tested two approaches: (1) a flat-tool geometry, in which a stamp supported by a rigid backplane is brought into contact with the substrate, very much the same as when an optical contact mask is applied to a resist-coated wafer; and (2) a cylindrical-tool geometry, in which a thin-film stamp is wrapped around a cylinder and rolled over the substrate, as in a rotary press.

With the first approach, a $100-\mathrm{mm}$ diameter and 1-mm thick Sylgard ${ }^{\circledR} 184$ layer molded with high accuracy directly onto a quartz mask plate (Fig. 7c) was used

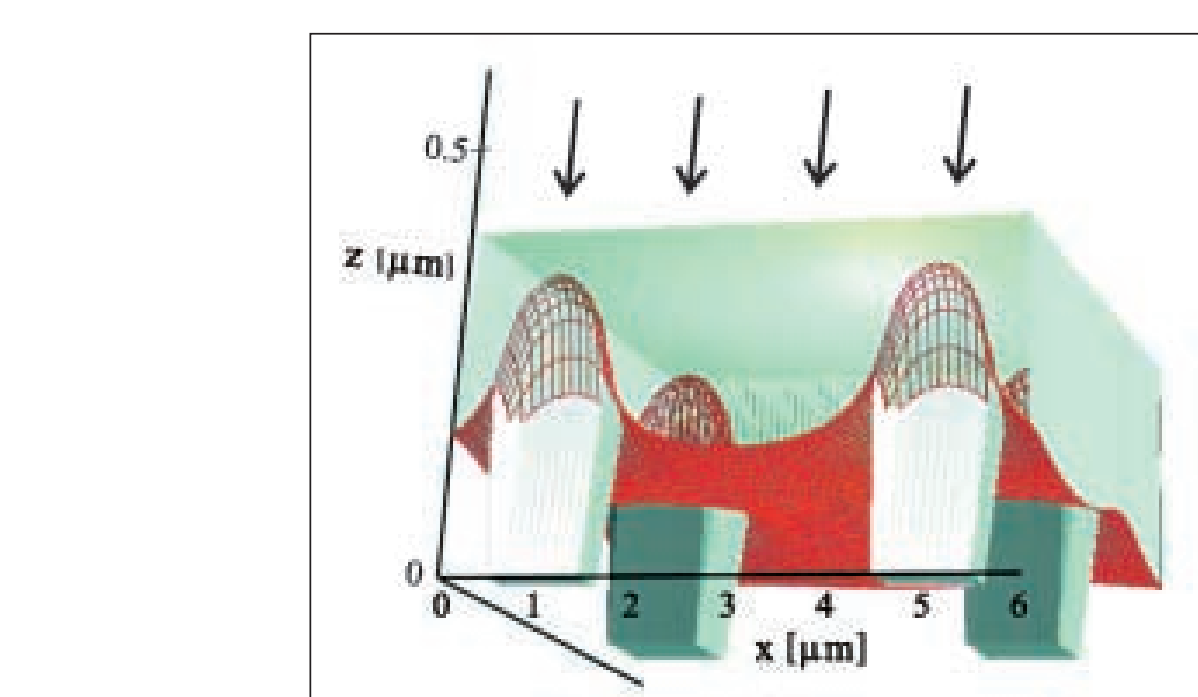

(a)

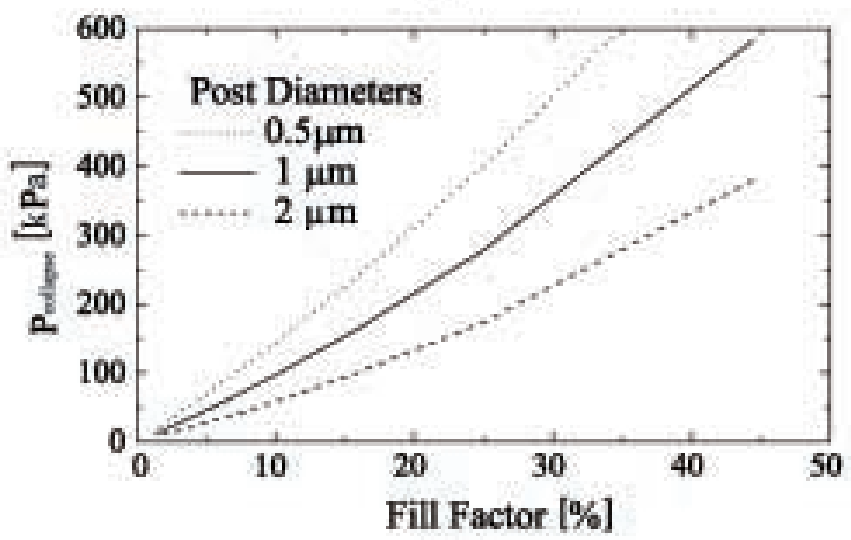

(b)

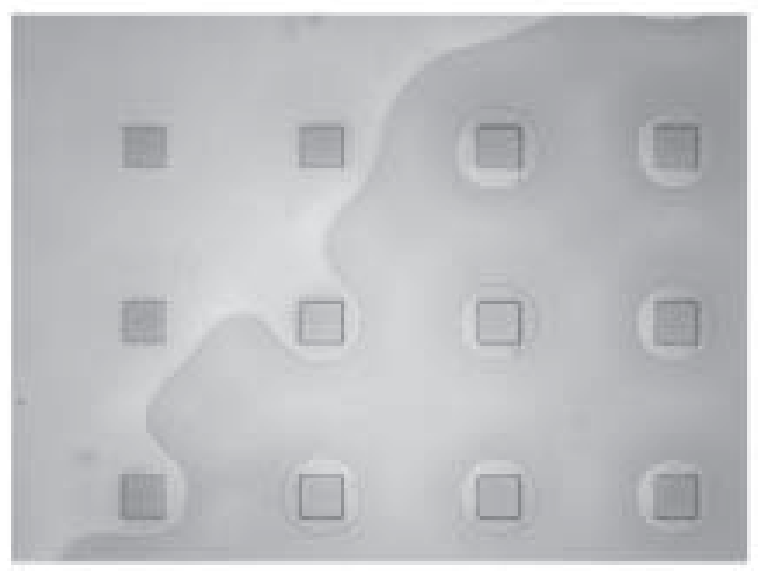

(c)

Fig. 8. Pressure-induced deformation of posts on a stamp with a modulus of $3 \mathrm{MPa}$. (a) Posts $1 \mu \mathrm{m}$ wide, $0.45 \mu \mathrm{m}$ high, and spaced $4 \mu \mathrm{m}$ apart distorted by an external pressure of $40 \mathrm{kPa}$. The red mesh represents the deformed base plane. (b) Pressure for onset of collapse as a function of fill factor and post sizes. (c) Optical micrograph of collapsed patterned stamp in contact with a glass substrate. Reprinted with permission from [42]. Copyright 2000 American Institute of Physics. 
for printing together with a modified bond aligner (EV420, Electronic Vision, Schaerding, Austria). Planar printing with these stamps was challenging because they allowed no control over the propagation of the contact front, which led to pockets of trapped air. More reliable radial propagation of the contact front was achieved by spherical deformation of the substrate or a stamp that was released after initial contact of the two surfaces. This approach remained problematic because varying the contact force throughout the process resulted in frequent collapse events, and the limited compressibility of polymers imposed very tight mechanical tolerances for highresolution printing. With a $30-\mu \mathrm{m}$ thick, hard polymer layer on a softer cushion (Fig $7 \mathrm{a}$ and $7 \mathrm{~b}$ ), the requirements concerning substrate and stamp flatness could be relaxed; but printing still could not be done routinely. With the flat-stamp approach, the maximum pattern distortion between two prints was $\sim 1.5 \mu \mathrm{m}$ over $75 \mathrm{~mm}$ but depended on the thickness of the polymer layer [57-59]. The drawback of a classical platen press is the unfavorable scaling of the separation forces with the printed area, which limits this approach to small areas [59][60]. In our soft-lithography platen press, no external print force is needed because the work of adhesion ensures fullarea contact, whereas releasing a rigid 4-inch stamp from a substrate (or master) may require up to $100 \mathrm{~N}$.

The second approach was based on the use of a thin-film stamp and a 400-mm radius printing cylinder. For printing areas of the order of $100 \mathrm{~mm} \times 100 \mathrm{~mm}$, we did not build a full cylinder but only an arc similar to the rockers of a rocking chair; the arc was mounted on a modified mask aligner (EV420). Thin-film stamps (Fig. 7d) for this tool were made by molding a 30- to $200-\mu \mathrm{m}$ thick prepolymer layer against a flexible, 75 - to $150-\mu \mathrm{m}$ thick Invar ${ }^{\circledR}$ steel, or glass backplane and the master. After curing, the thin, flexible backplane with the polymer layer was gradually peeled away from the master. The thin-film stamp was mounted on the print cylinder and then brought into contact with the substrate with the rocker tilted fully to one side. After wedge compensation, a contact line was established which was moved over the entire print area by a rocking motion. Printing

Fig. 9. (a) Optical micrograph of a gold pattern on a 4-inch wafer was printed using a thin-film stamp mounted on a cylinder followed by a selective etch. (b) Difference map between print and master; printing direction is from bottom to top. (c) Distortion map after compensation of $-245 \mathrm{ppm}$ isotropic shrinkage and $+77 \mathrm{ppm}$ cylinder-induced stretching along the print direction. speeds varied between 0.1 and $10 \mathrm{~mm} / \mathrm{s}$, and applied forces were adjusted between 0.5 and $10 \mathrm{~N}$. The width of the contact zone between the stamp and the substrate was approximately $2 \mathrm{~mm}$, leading to maximum pressures of $40 \mathrm{kPa}$. A gold pattern printed using these conditions is shown in Fig. 9a. The requirements imposed on the mechanical precision of the drum, the thin-film stamp, and the substrate can be considerably relaxed when a soft tape $(0.5 \mathrm{~mm}$, Tesa Softprint $\left.{ }^{\circledR}\right)$ is inserted between cylinder drum and stamp to level out mechanical in- homogeneities, as is commonly done in flexography. This is especially helpful if the stamp is made of a harder elastomer for high-resolution application or if the pattern stability is low.

Accurate printing (Fig. 9) with the 'rocker' cylinder printing tool required an anisotropic compensation of the wrappinginduced elongation along the printing direction (as in a rotary press) in addition to the isotropic compensation needed because of thermo-curing-induced shrinkage of the stamp. Factors for compensating the

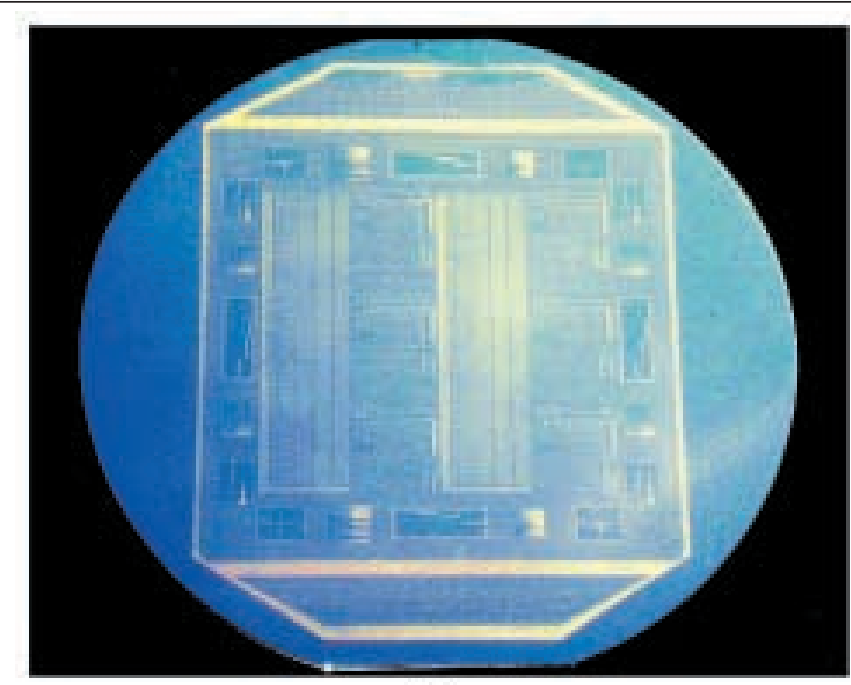

(a)

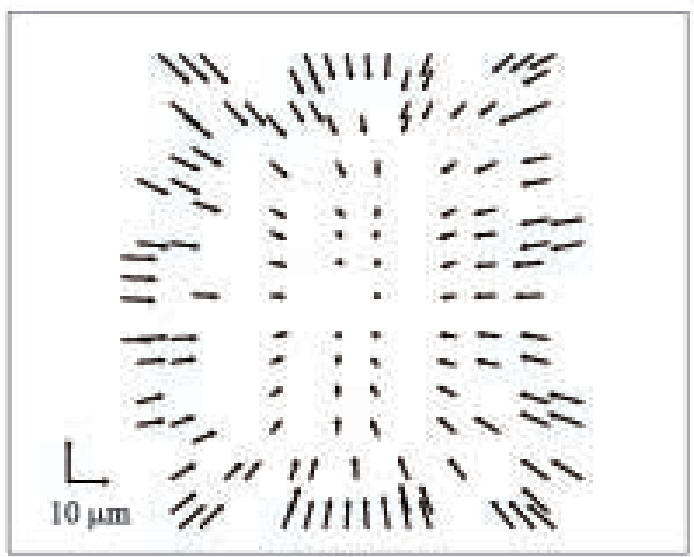

(b)

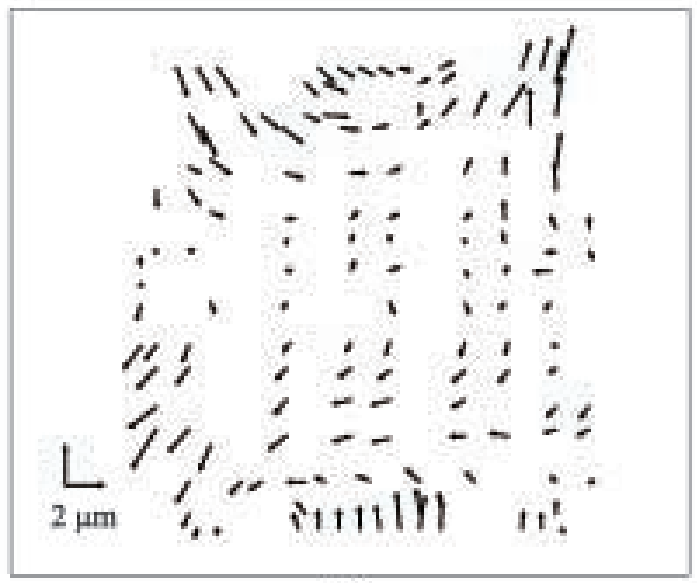

(c) 
isotropic shrinkage were calculated using thermal expansion coefficients. In our case we calculated a temperature-dependent shrinkage of $-250 \mathrm{ppm}$, and experimentally found a shrinkage of -245 ppm (Fig. 9b). The factor for the anisotropic, cylinder-induced stretch had to be determined experimentally. A geometrical calculation resulted in a stretch of $+125 \mathrm{ppm}$, whereas the stretch found experimentally was $+77 \mathrm{ppm}$ (Fig. 9b). Maximum distortions of prints were of the order of $2 \mu \mathrm{m}$ over a dimension of $65 \mathrm{~mm}$, and had a relative error of $30 \mathrm{ppm}$. The average statistical errors from print to print were typically $0.8 \mu \mathrm{m}$ or $12 \mathrm{ppm}$ (Fig. 9c). Overlay added $\pm 1 \mu \mathrm{m}$ to the error budget due to optical and mechanical limitations of the tool used. It may be advantageous to combine the platen press and cylinder approaches (flat printing and cylinder-driven peeling) because this combination does not need anisotropic compensation and allows low-force peeling. However, such tools would have to be more complex than other printing tools.

Long-range placement accuracy is already an issue in 'flat' printing approaches with hybrid stamps on solid mask plates. The placement accuracy of patterns printed with thin-film stamps is even more difficult because of mounting on a cylinder, geometric inaccuracies, and shear forces induced by the printing tool. Reaching sub-10 ppm lateral accuracy (standard deviation between subsequent prints made with the same stamp and systematic error) requires control of more parameters than those mentioned above. For printing techniques to become relevant to microelectronics, a 1-ppm accuracy level is required - a truly challenging task.

\subsection{Characterization of Conductive Printed Structures}

Reproduction accuracies of soft lithography have been characterized using optical and SEM-based metrological equipment for lateral measurements, and white-light interferometric microscopy and AFM for three-dimensional profiling (see above). For patterned conductive structures, electrical characterization was more informative because it directly tests whether structures

Fig. 10. Electrical metrology of microcontact-printed wires. (a) Scheme of conductivity measurements. (b) SEM overview of printed and etched array of 125-nm wide Au wires on $\mathrm{SiO}_{2}$. (c) Inset imaged by the conducting AFM; the path of electrical probing is indicated by red arrows/dashed line. (d) Results of wire probing with the resistance data (squares, left-hand scale) and topography (line, right-hand scale). Intact wires have a resistance in the green zone, whereas the resistance of defective wires is located in one of the pink zones. are suitable as interconnects. Electrical testing with today's chip probers was too harmful for direct measurements on our submicrometer-sized structures because we did not include test pads in our designs.

We therefore devised a method for the reliable, reproducible electrical testing of nanoscale wire arrays using conducting probe AFM under ambient conditions [61]. Metallic nanostructures on the wafers were identified by topographic imaging and subsequently probed using the same AFM tip as mobile electrode (Fig. 10). The conductivity of individual gold wires was measured directly with a conductivity-probing setup (Fig. 10a). Gold wires of $125 \mathrm{~nm}$ width, $22 \mathrm{~nm}$ thickness and $400 \mu \mathrm{m}$ length were connected at both ends by interconnect meshes (Fig. 10b and 10c). The resistivity of the wires was $31.7 \pm 0.8 \Omega / \mu \mathrm{m}$, and the density of defects was 0.7 per mm of wire (Fig. 10d). Thinner gold wires (30-50 $\mathrm{nm}$ ) showed higher average resistivities and, in some places, resistance steps of individual grain boundaries [62].

The ability of this instrument to address both topographical and electrical characteristics with high spatial resolution has been used to assess the yield of our high-resolution printing technique. Although these measurements are still ongoing, a preliminary result is that defect counts do not increase even when stamps are used more than a hundred times in a clean environment. Overall, defect counts are already sufficiently low for structures such as highresolution diffractive optical elements and low-resolution microelectromechanical-system (MEMS) patterns to be printed in large numbers with sufficient reliability.

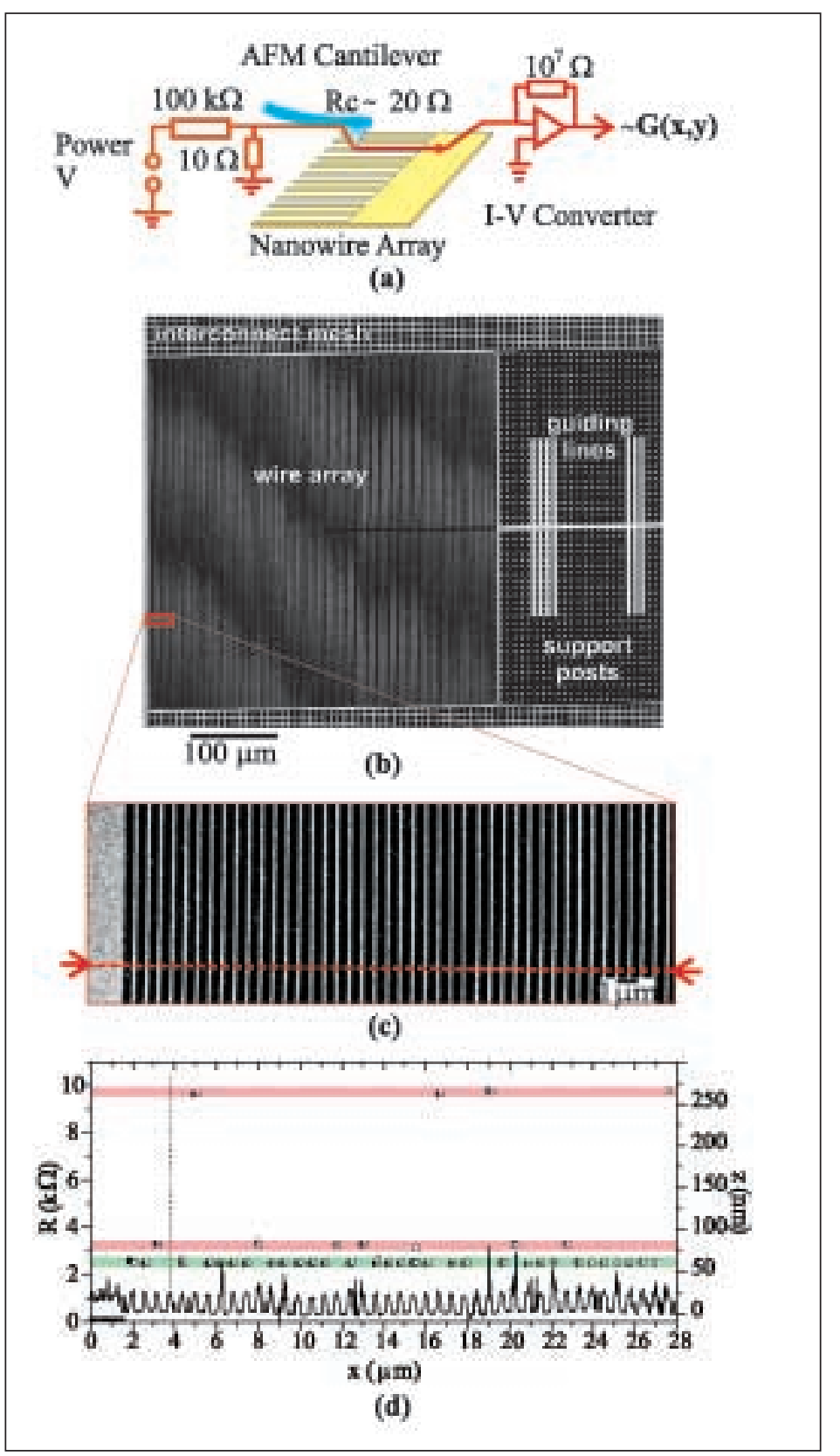




\section{Applications and Alternative Replication Schemes}

Direct processing of substrate surfaces to chemically change, remove, or add material is the goal of our research and development effort. Two schemes exist: In the first, the process is localized at the contact area of protrusions, as for flexography. In the second, the contact areas protect the substrate and define a pattern of nonprotected areas exposed to the reagents, as for intaglio and screen printing. We show here several methods of contact transfer and processing - some of them extending beyond the scope of classical printing schemes.

\subsection{Patterning of Fluids and Processing of Surfaces}

In the past, printing and soft lithography have been used exclusively in the classical one-stamp, one-ink, one-transfer scheme. With this scheme, the execution of several processes or the patterning of several dyes requires the use of several stamps printed in a consecutive fashion with precise alignment on the final substrate. In photography, the very first attempts to reproduce colors also used an overlay of three pictures taken separately with different filters. Color photography then underwent a spectacular development with the introduction of color films that combine three different sensitivities on one film [63]. Similarly, in current color printing, images are separated into three or four colors and printed with precise alignment in subsequent steps onto the final surface. Color printing never experienced a development that would have allowed colored images to be printed in one step (with the exception of ink-jet printing).

We present several approaches for the selective placement of single or multiple chemicals with inherent alignment. These methods rely on a similar process flow: (1) the structured transfer medium is applied to the substrate and seals adjacent recessed regions from each other; (2) different substances are guided and delivered to distinct regions of this substrate; (3) the substances are immobilized and processed chemically once they have reached their desired location; and (4) the transfer medium is removed (Fig. 11).

Selective filling and de-wetting is comparable to writing with a pen, but differs in that 'ink' de-wets the surface and is selectively trapped in small cavities (Fig. 11a) [64]. With this technique, a liquid or chemical can be selectively delivered to a patterned surface, provided that the interactions among the wetting property, the geometry of the wells, the delivery tip, and the speed of displacement are appropriate.

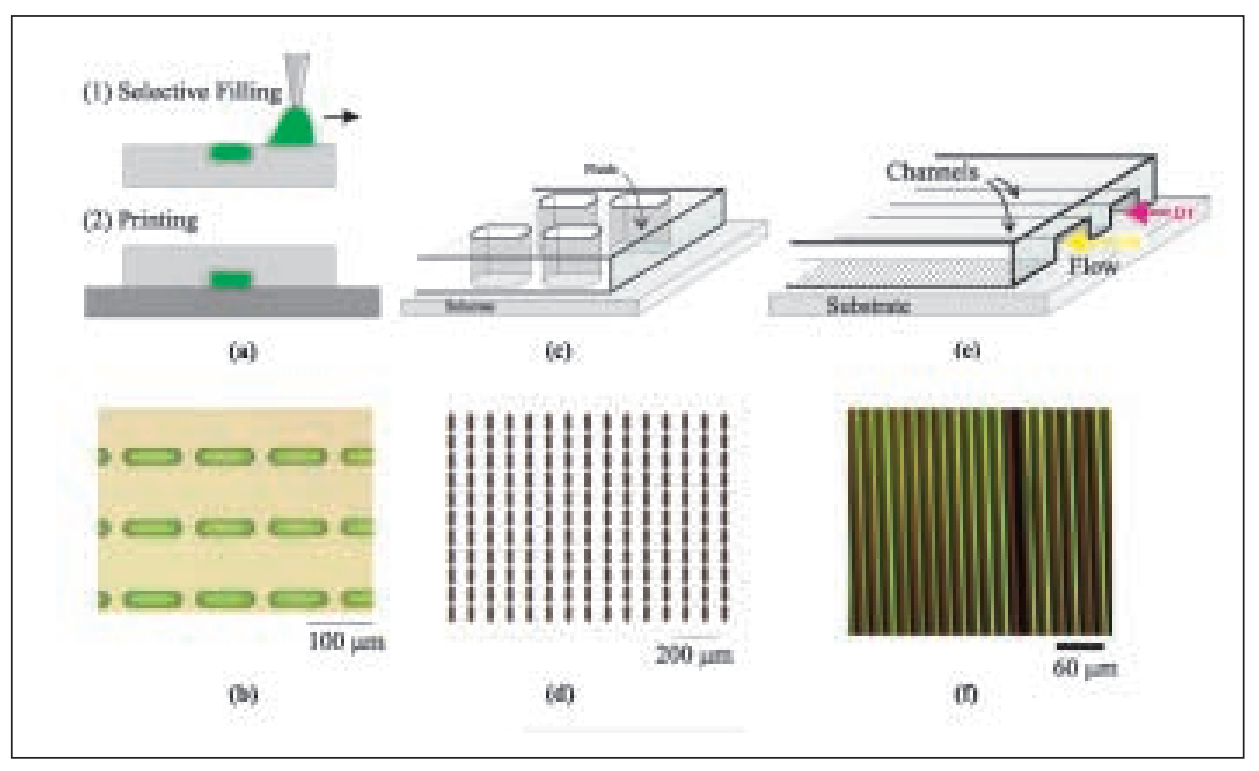

Fig. 11. Directed processing of a substrate with fluids. (a) Serial selective filling of cavities in patterned substrates (writing). (b) Optical image of PDMS cavities $(25 \mu \mathrm{m} \times 75 \mu \mathrm{m}, 20 \mu \mathrm{m}$ deep) selectively filled with a dye. (c) Lids placed in contact with a substrate localize a chemical reaction (screen printing). (d) Optical image of an array of openings $(25 \mu \mathrm{m} \times 100 \mu \mathrm{m}, 380 \mu \mathrm{m}$ deep) in a Si wafer. (e) Microfluidic networks for guiding of several fluids (D1, D2) for parallel processing (extended intaglio, molding). (f) Image of fluorescence from dyes dispersed in a polymeric carrier patterned using an interdigitated microfluidic network.

A chemical reaction can take place in each cavity after the cavity has been filled, or a compound may be permanently placed there. The selective filling of cavities in a PDMS layer with a colored material provides an example of such a processing strategy (Fig. 11a and 11b).

If selective filling and de-wetting cannot be achieved, the pattern can be provided by applying a layer with open cavities to the substrate (Fig. 11c and 11d). Lids with selective openings can be filled with a processing fluid before or after they are placed in contact with a substrate. The patterning device shown in Fig. 11 consists of a $\mathrm{Si}$ wafer with holes etched through its entire thickness. Low-viscosity fluids can be processed when an elastomeric substrate such as PDMS prevents gaps by a conformal contact between the substrate surface and the solid parts of the screen.

Finally, microfluidic networks can be brought into contact with a substrate and used to transport a liquid to a desired location far from its original delivery port (Fig. 11e and 11f) [65-67]. They complement the previous two techniques (Fig. 11a,b and 11c,d). Accurate pattern replication requires a good wettability of the channels by the processing fluids and compatibility between network material and these fluids. Reactions localized by microfluidic networks covering a substrate include the dissolution of a substrate with a mild base or acid, the conversion of chemical functionalitites on the surface, and the deposition of polymers, biological molecules, or catalytic particles.

We have demonstrated liquid contact processing over length scales from millimeters down to micrometers for a variety of substrates including viscous and volatile inks [68]. The strength of these methods lies in the patterning of materials (e.g. polymers, biological molecules) that are incompatible with classical resist processes. Combinations of the three approaches described above (i.e. of cavities or lids and microfluidic networks (Fig. 11c and 11e) or of stamps and lids or fluidic networks (see below)), allow more complex processing schemes that extend printing to a one-stamp, multiple-ink, multiple-pattern scheme. Thus they may help to improve the printing performance because only one operation allows multiple chemicals to be transferred and patterned on a substrate with inherent alignment.

\subsection{Patterning of Biomolecules}

Arrays of surface-bound biomolecules [69][70] find applications in biosensors, chromatography, diagnostic immunoassays, cell culturing, DNA microarrays, and other analytical procedures. Among these applications, diagnostic immunoassays and DNA sensing are the driving forces in the effort to miniaturize biological assays and to conduct many assays in parallel. This trend offers several advantages. In small volumes, mass transport by diffusion can be fast, and chemical reactions can be acceler- 
ated accordingly. The solutions are used more efficiently, and lower volumes of samples or reagents are required. The small dimensions make biochemical reaction systems amenable to parallelization and large-scale integration. Small scales can be crucial to the realization of certain types of assays, for example where laminar flow in capillaries is required [71] or where fast heat dissipation can reduce processing time, as in a polymerase chain reaction (PCR) [72].

The main advantage of printing over standard procedures for making arrays is the capability of processing large bioactive surfaces in one 'run' with arbitrary patterns. To expand the range of possible applications [73][74], we devised schemes to pattern the same surface with several different proteins [75]. There are two ways to print different proteins onto a single substrate using soft-lithographic techniques: (1) successive, iterative inking and printing and (2) parallel inking of a stamp followed by a single printing step. Fig. 12a shows the general procedure of the iterative approach, in which different stamps having different patterns and/or inks are printed many times onto the same substrate. Biomolecules (such as proteins or enzymes) adsorb spontaneously to the hydrophobic surface of a stamp by incubation with an aqueous solution of the desired molecules for several minutes. Using an array of $80-n m$ posts made from PDMS with a high modulus, we were able to print single antibody molecules (Fig. 12a, part V).

As in offset printing, a planar stamp can be used as a vehicle for transferring proteins patterned on the planar stamp to the target surface [76]. The main challenge in performing such parallel printing is to obtain a stamp inked locally with different proteins. Any patterning-by-adsorption method is suitable, provided that it does not compromise the mechanical properties and the pattern of the stamp. Fig. 12b illustrates the use of microfluidic networks to define the areas of inking [66][67]. Unlike diffusive inks (e.g. thiols or metallic ions) [67][76], proteins remain accurately placed on the flat stamp and can then be transferred to the substrate. To achieve higher-resolution printing with standard PDMS (Sylgard 184), we used 'subtractive inking', a process unknown in classical printing (Fig. 12c). Here, a flat stamp is homogeneously inked with a protein of interest. The protein layer is patterned by selectively removing patches of protein from the stamp by contacting the stamp with a microstructured 'negative' pattern. The residual pattern is then printed to the substrate. As there is no risk of collapse with flat stamps, we

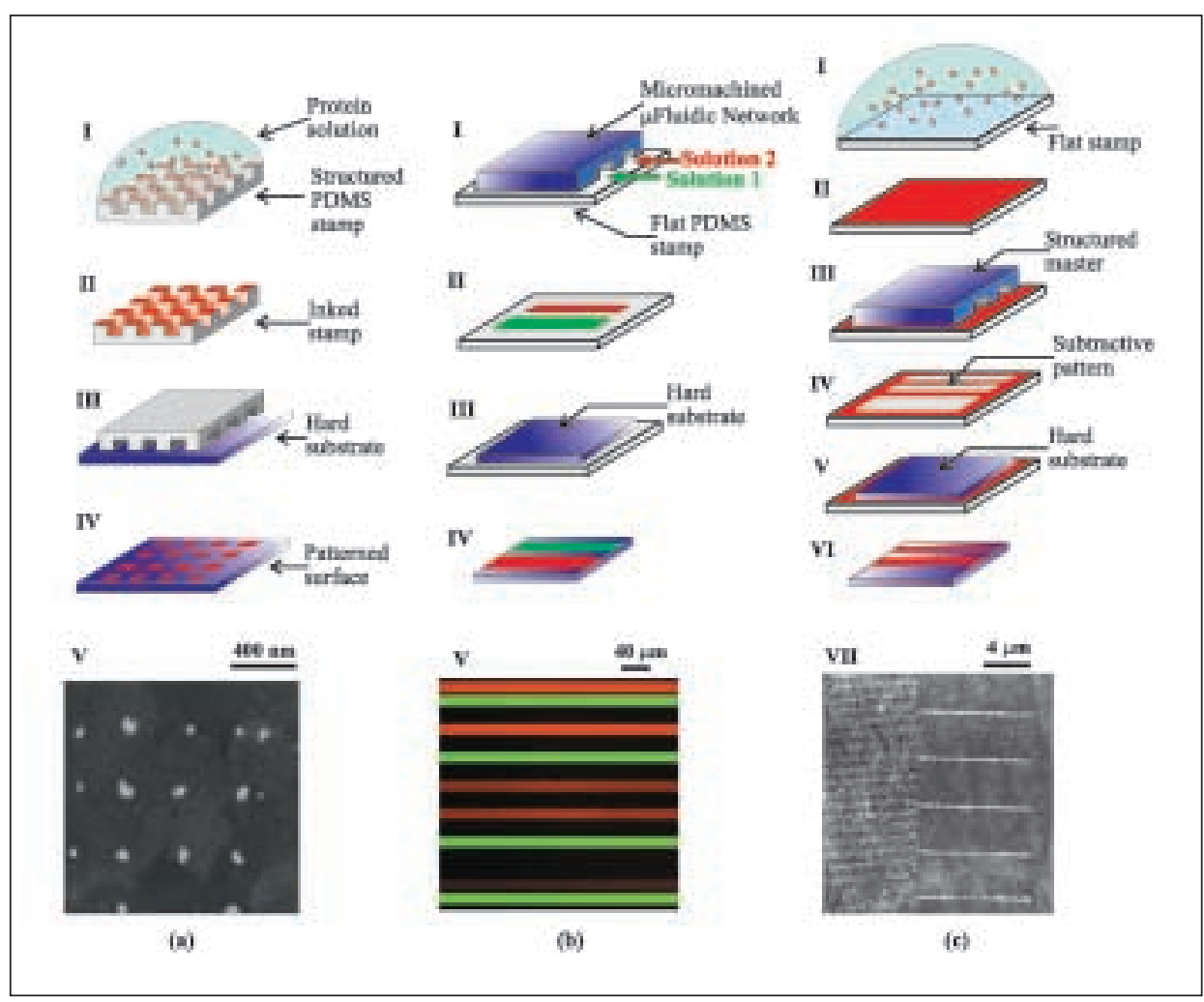

Fig. 12. Printing of biological molecules. (a) Direct printing: (I) A patterned stamp is inked with a solution of proteins (II), which are transferred efficiently (>99\%) by brief contact (III) with the substrate surface (IV). (V) AFM image of individual immunoglobulin molecules printed onto glass. (b) Localized inking and offset printing: (I) A microfluidic network creates lines of different proteins on a flat stamp (II); these are transferred (III) to the substrate (IV). (V) Image of fluorescence from sixteen different proteins on polystyrene (not all proteins are labeled). (c) Subtractive offset printing: (I) The stamp is inked with a protein (II), (III), which is brought into contact with a patterned silicon surface (IV), and transferred to the silicon. The remaining molecules are printed $(\mathrm{V})$ to the substrate surface (VI). (VII) AFM image of 100-nm lines of proteins.

expected the resolution of subtractive printing to be limited only by the resolution of the structured master used in the subtractive step. Indeed, a resolution of 100-200 nm was achieved using subtractive printing with standard PDMS (Fig. 12c). For feature sizes smaller than $100 \mathrm{~nm}$, subtractive printing was not efficient enough to allow the preparation of a perfect pattern.

\subsection{Printing of Catalysts for Electroless Deposition of Metals}

The capability of printing to transfer chemical reagents from an elastomeric stamp to a substrate can be used to direct the electroless deposition (ELD) of copper. Electroless deposition is a wet chemical metallization process that entails the reduction of a salt from solution onto a surface using a reducing agent as the source for electrons [77-79]. The presence of a catalyst on this surface is necessary to initiate ELD before the deposition can proceed in an autocatalytic manner. The combination of printing with ELD of a metal, such as copper, is of scientific as well as technological interest [80]. So far, all approaches have used solvents that interfere with the chemical and topological integrity of PDMS stamps. For this reason, we examined printing of $\mathrm{Pd}(\mathrm{II})$-based catalytic precursors soluble in solvents compatible with high-resolution PDMS stamps [81].

Fig. 13a illustrates the experimental procedure. Practically, this method relies on two key steps: First, the stamp surface is made hydrophilic with an $\mathrm{O}_{2}$ plasma to greatly increase the affinity between the stamp and a variety of ethanol- and watersoluble Pd(II) species, allowing the stamp to be inked with these compounds. Second, the substrate is pretreated before printing to ensure adhesion of the catalyst to the surface. For our application, the evaporation of a thin layer of titanium onto the substrate, such as a silicon wafer, proved to be the preconditioning method of choice, because conventional pretreatments of the substrates with $\mathrm{SnCl}_{2}$ or aminosilanes did not produce satisfactory results. Titanium provides two major functions for printing a Pd(II) catalytic precursor onto a surface: First, it immobilizes and reduces Pd(II) during printing; second, it is an efficient pro- 
moter of adhesion between the substrate and the $\mathrm{Cu}$ deposit. The electroless deposition of copper was achieved by immersing the activated samples in an alkaline $\mathrm{Cu}$ tartrate bath containing formaldehyde as the reducing agent.

The accuracy, contrast, and resolution of the $\mathrm{Cu}$ patterns produced by printing and ELD, in addition to their quality, homogeneity, and adhesion to the substrate, are the most important criteria for evaluating the merit of combining these two techniques. Fig. 13b demonstrates that printing a $\mathrm{Pd}(\mathrm{II})$ catalytic precursor can lead to $\mathrm{Cu}$ structures with linewidths of $170 \mathrm{~nm}$, for example, when high-resolution stamps provide the pattern. Here, $\mathrm{Cu}$ grains having a diameter between 80 and $170 \mathrm{~nm}$ appear to be continuously connected and form the lines on the substrate with good accuracy, suggesting a homogeneous distribution of the catalyst in the printed patterns. The high contrast indicates that no catalyst has diffused away from the zones of print and that ELD of $\mathrm{Cu}$ was strictly limited to the catalytic areas of the substrate.

It is difficult, however, to determine the precise influence of the parameters of the plating conditions, such as composition, strength, stability, and temperature of the plating bath, on the highest resolution achievable using printing and ELD of $\mathrm{Cu}$. In the limit, the particle size of $\mathrm{Cu}$ grains can be as low as $5 \mathrm{~nm}$ for deposits on activated surfaces. By combining improved stamp fabrication for high-resolution printing with an appropriate $\mathrm{Cu}$ ELD process, feature sizes of about $50 \mathrm{~nm}$ are thought to be achievable.

\subsection{Light-Coupling Masks}

Six years ago [19], we set out to find an alternative to optical lithography. Our efforts took an unanticipated turn, however, when we realized that our stamps can be used in an optical contact lithography scheme. PDMS is transparent for wavelengths down to $256 \mathrm{~nm}$, and it makes conformal contact with a substrate, which minimizes reflection of light at the interface. Structured PDMS stamps thus selectively guide electromagnetic fields through the interfaces in contact. These so-called 'lightcoupling masks' (LCMs) or, more casually, 'light' stamps [82-86] are composed of a transparent backplane and a PDMS materi- al with a refractive index $(n)$ matching the resist, and in some cases an absorbing layer in recessed zones. They are placed on a resist-covered surface and exposed to short-wavelength light. As in the other areas of soft lithography, the mask must have the same feature sizes as the final product. The small protruding features on the stamp, which are surrounded by air gaps, collimate and intensify the incoming light, which is then coupled into the photoresist and subsequently developed with a standard procedure. To understand the propagation of the electromagnetic wave through the pattern into the resist, extensive simulations have been performed (Fig. 14a) [87-89]. Simu- lations and experiments (Fig. 14b) reveal that the LCM technique is wavelength-dependent but can approach the physical limit given by $\operatorname{Res}=\lambda /(2 n)$ much more closely than 'hard' contact lithography [12]. For our choice of wavelength $(\lambda=248 \mathrm{~nm})$ and material $(n=1.5)$, we predicted a limitation at feature sizes of $80 \mathrm{~nm}$. Beyond that, the contrast function and depth of exposure are diminishingly small. Experiments have shown that features with sizes down to $120 \mathrm{~nm}$ at a pitch of $240 \mathrm{~nm}$ can be reliably reproduced. Other concepts of high-resolution contact lithography that use amplitudecontrast masks also rely on improving the contact between the absorber and the resist (a)

(b)
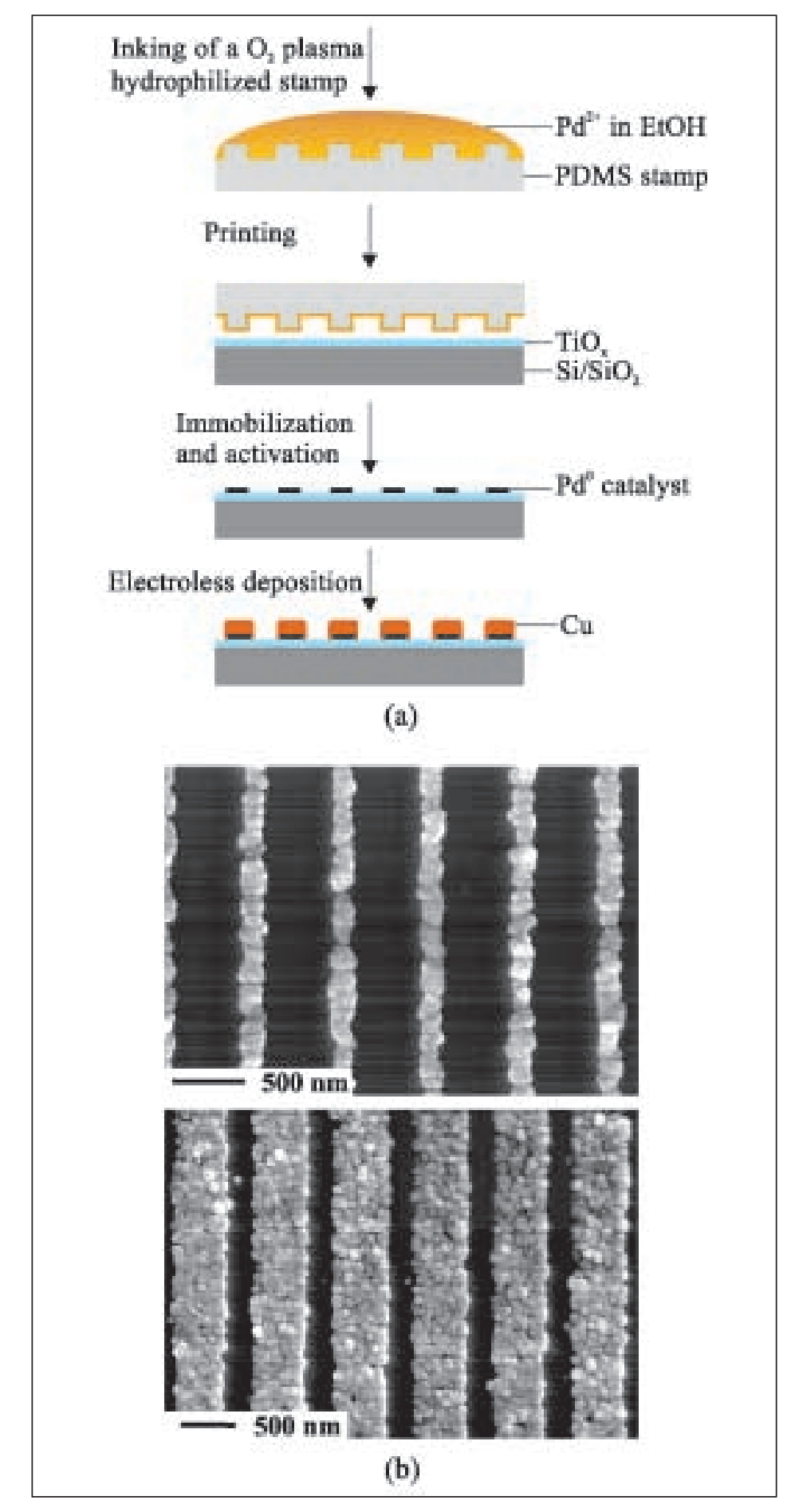

Fig. 13. (a) Procedure for selective electroless deposition of $\mathrm{Cu}$ by printing a $\mathrm{Pd}(\mathrm{II})$ catalyst onto a Ti-coated $\mathrm{Si} / \mathrm{SiO}_{2}$ wafer. (b) SEM images of $\mathrm{Cu}$ deposited onto catalytic Pd lines obtained by printing bis-(stearonitrile)palladium-dichloride with a high-resolution stamp (Adapted with permission from [81]. Copyright 2000 American Chemical Society). 
by the use of embedded amplitude masks [90] or very thin absorbing membranes with openings [91], which conform better to the resist than do traditional hard masks.

The light-stamp example described above demonstrates that there is no strict boundary between printing and optical or X-ray [92] contact lithography - it seems that both approaches can yield comparable results. Limited durability of stamps or masters is generally assumed for contact lithographies. The printing industry, however, has demonstrated that the durability of stamps involved in contact transfer can allow high replication factors, which compensate for high initial costs of master and stamps.

\section{Discussion and Outlook}

The common feature of all of the printing methods discussed here is conformal contact of an elastomer with a hard surface, in which either the hard surface or the elastomer is patterned topographically or chemically. Soft lithography makes use of almost all replication schemes known from classical printing and introduces a few novel schemes. During a printing step, an ink may be transferred to the substrate (additive print) or removed from the substrate (subtractive print), the chemical nature of the substrate may be altered in the zones of contact (convertive print), or the substrate itself may be selectively removed (etching).
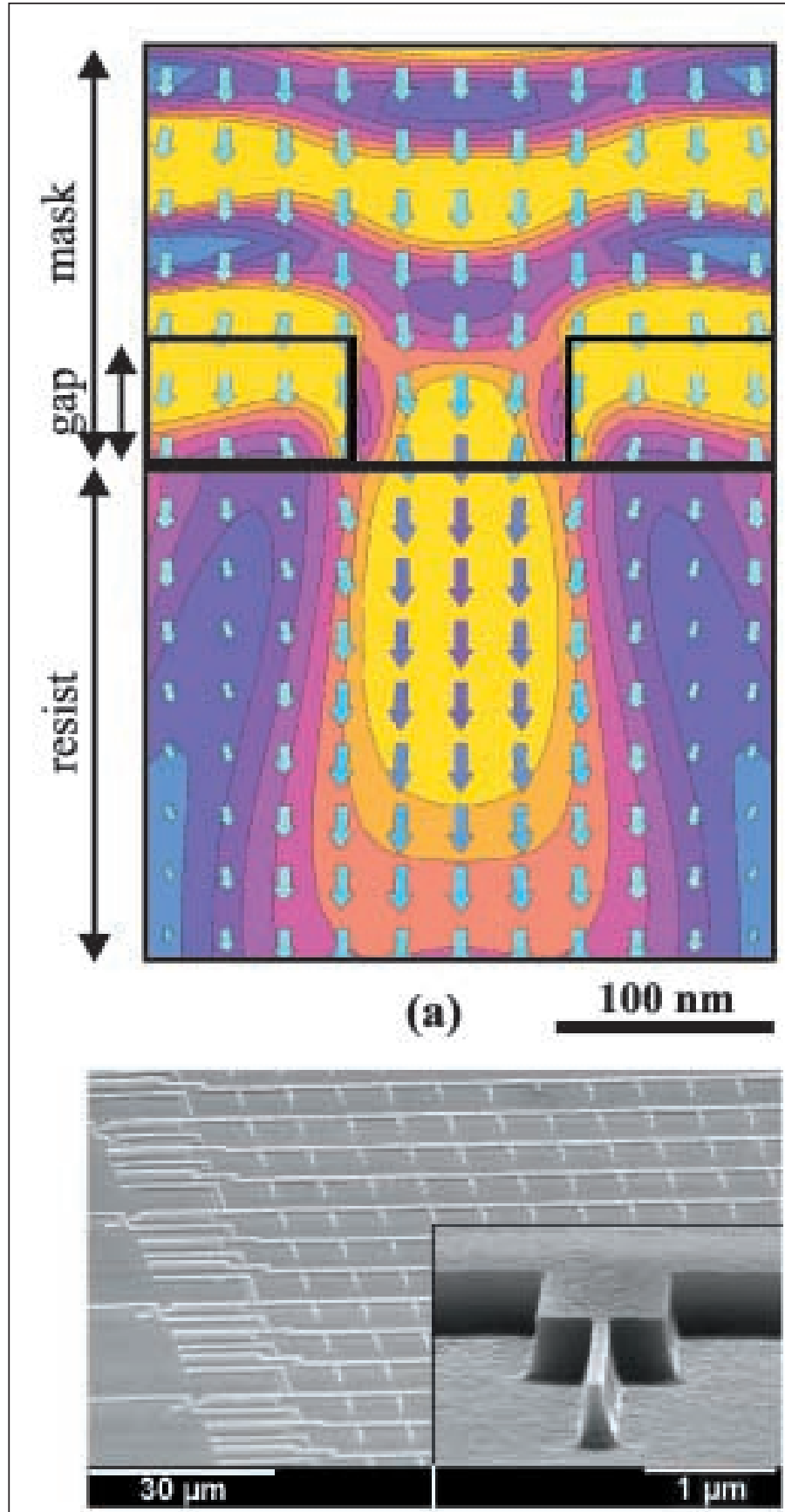

(b)
Additional examples of additive processes are patterning, curing, and releasing of structures such as waveguides using polymers cured by ultraviolet light [93-95]. Electroless deposition of metals and patterned catalytic growth of carbon nanotubes [96-98] provide examples of an additive print with subsequent pattern amplification. An example of the convertive approach would be to mediate a surface reaction by providing a reactant with a print or to render a substrate on a surface selectively insoluble. Subtractive printing has been used for biopatterning [75] and multicolor screen printing for patterning of dyes.

From the Table it is apparent that soft lithography makes use of most of the established printing schemes in the scope of the 'one ink-one print' approach. Combining printing with microfluidics and controlled sealing has allowed printing schemes to be extended to a 'many inks-one print' approach, referred to as multicolor screen printing, which can generate more powerful replication schemes.

The offset approaches discussed in the context of biological printing were also useful in patterning catalysts for the electroless deposition of metals [76]. They are superior in terms of pattern accuracy in cases where ink molecules do not diffuse and blur the contrast. Ink dosing is in general an important issue in accurate printing. In flexography this has been solved by using an inking roll with tiny depressions that hold an exactly metered amount of ink. Wellcontrolled inking may also become necessary in soft lithography. Self-assembledmonolayer-forming inks should offer a fair process window because the transfer of ink is largely self-limiting. An equivalent to electrostatic patterning in the micro world may be the field-induced self-construction of polymer microstructures [99-101] and the charge patterning in thin organic films [102]. Subtractive printing has been used for biopatterning, and multicolor screen printing for patterning of dyes. Optical printing is discussed in the section on lightcoupling masks. New approaches for direct contact-mediated transfer of individual molecules or nanoparticles allow self-as-

Fig. 14. (a) Simulation of the propagation of 248-nm light through a $100-\mathrm{nm}$ wide LCM with $60-\mathrm{nm}$ air gaps. Contours are isointensity lines from a three-dimensional simulation scaled in increments of $10 \%$ with white as the highest intensity. Arrows indicate the timeaveraged Poynting vector. (b) SEM image of positive resist (UV5, Shipley) exposed with LCM having a mixture of small (120-nm) and large features and using 256-nm light. The structure height of the LCM was $100 \mathrm{~nm}$ with no additional absorbers. Reprinted with permission from [82]. Copyright 1998 American Institute of Physics. 
Table. Comparison of classical printing techniques with their soft-lithography analogs.

\begin{tabular}{|c|c|}
\hline Printing Soft & Lithography \\
\hline $\begin{array}{l}\text { Flexography (relief printing) } \\
\text { - " - with offset }\end{array}$ & $\begin{array}{l}\text { Microcontact printing } \\
\text { Flat stamps }\end{array}$ \\
\hline Intaglio printing & Microcontainers (microwells) \\
\hline - " - with offset & Transfer via flat elastomeric intermediate \\
\hline Screen printing & Printing through openings in a membrane \\
\hline - " - with offset & Transfer via flat elastomeric intermediate \\
\hline $\begin{array}{l}\text { (Stone) lithography } \\
\text { (wettability contrast) }\end{array}$ & No demonstration so far \\
\hline - " - with offset & Transfer via flat elastomeric intermediate possible \\
\hline Electrophotography & Charge patterning in thin organic films \\
\hline $\begin{array}{l}\text { Novel schemes: } \\
\text { (Inverse relief offset printing) }\end{array}$ & $\begin{array}{l}\text { A flat stamp is homogeneously inked, and material is } \\
\text { selectively removed }\end{array}$ \\
\hline (Multicolor screen printing) & $\begin{array}{l}\text { Selective addressing of groups of openings in } \\
\text { screen printing } \\
\text { Microfluidics for multiple inking }\end{array}$ \\
\hline (Optical contact printing) & Optical contact printing with conformal contact \\
\hline
\end{tabular}

sembly to be combined with printing to create more powerful manufacturing methods for the years to come. In such schemes, nanostructured stamps will direct or assist the self-assembly of structures by pattern matching. It appears that DNA hybridization [103][104] and biological recognition on novel 'transfer devices' may play a role in future semiconductor manufacturing, either as structuring aid [105] or to obtain more powerful coding schemes [106].

Demonstrations of the fabrication of devices using soft lithography are still fairly scarce and include relatively large structures: Arrays of metal oxide on semiconductor field-effect transistors (MOSFETs) with a gate size of $20 \mathrm{~mm}$ were fabricated [107]. GaAs/AlGaAs MOSFETs were fabricated in a similar way [108]. Arrays of $\mathrm{Al} / \mathrm{Si}$ Schottky diodes with 2- to $100-\mathrm{mm}$ gaps have been demonstrated using printing of alkanephosphonic acid and etching on $\mathrm{Al}$ [109]. Electrodes for organic electronic applications have also been patterned [110]. Soft lithography is able to create patterns for MEMS [111], but the possibilities of the technology have not been fully exploited in these examples. Compelling reasons to switch to this new technique are the ability to process very small structures and to pattern materials that are incompatible with resist processes. The direct patterning of conducting polymers appears to be an example of a niche application for soft lithography [2].
We have shown that high accuracy is achievable with soft lithography, but alignment issues remain a challenge. When the size of the exposure field is reduced, optical steppers reach 30-nm overlay and accuracy [9]. However, this does not mean that exposures are absolutely accurate to $30 \mathrm{~nm}$ because they are exposed on wafers that might have become distorted during the various heat steps by as much as $1 \mathrm{~mm}$. But because the new layer 'adapts' to the deformed substrate, the overall overlay accuracy is much better than the absolute accuracy. In a fashion similar to this, the presence of topographic features on the substrate that match inverse features molded into the stamp allows the implementation of an adaptive lock-and-key-type self-alignment for printing [19]. Adaptive approaches could greatly relax the demands for long-range accuracy for a slightly elastic system that is capable of physically 'feeling' the misalignment by mechanical contact, and adapting itself accordingly the technical feasibility of such concepts has yet to be demonstrated, however.

In the semiconductor industry, optical lithography approaches have been pursued with much more vigor than have printing approaches - it is therefore no surprise that they are predominant in the crucial patterning steps. However, the excessively high cost associated with semiconductor manufacturing is now beginning to slow down progress so that printing processes are be- ing reconsidered [112][113]. The annual revenue generated by the printing industry is comparable to that of the computer industry, which could have induced investments large enough to include high-resolution patterning. Judged on the recent past, however, this has not been the case, perhaps because of the smaller company sizes or the lack of corporate research among print-tool manufacturers. The development of soft lithography initially proceeded very rapidly and separately from the printing industry. Now, however, it will presumably merge with printing to create a new technology that may challenge optical lithographies in terms of throughput, cost per area, and high-resolution pattern replication. Triggered by promising applications with intermediate accuracy requirements, innovations might drive printing technologies to reduce pattern sizes from $20 \mathrm{~mm}$ to $100 \mathrm{~nm}$ and to improve overlay from $20 \mathrm{~mm}$ ( 20 ppm) to levels below 1 ppm. Largearea accuracy and overlay, however, demand additional efforts and possibly the introduction of adaptive concepts. Nevertheless, single-layer printing with reduced lateral-accuracy requirements (10 ppm, optical filters and gratings) and replication with overlay of larger patterns (micrometer scale) may soon be applied in niche markets. We are confident that our effort will help printing and high-resolution lithography to merge into a more powerful and versatile micro- and nano-scale patterning technology. 


\section{Acknowledgments}

We acknowledge partial financial support from the European ESPRIT basic research project NANOWIRES (23238), from the biotech European project BIOPATT (BIOCT980536), and from the Swiss National Science Foundation project NFP 36 . We are grateful to our colleagues U. Drechsler, H.-P. Ott, K. Wasser, and R. Widmer for technical support, and to H. Biebuyck, H.R. Bosshard, I. Caelen, C. Donzel, R. Fair, S. Hall, J. Hilborn, A. Hoole, F. Kamounah, E. Kiewra, N.B. Larsen, L. Libioulle, R. Magnusson, O.J.F. Martin, R. Nunes, M. Paulus, K. Schaumburg, and M.A. Schneider for their contributions and discussions. We also thank P. Guéret, K. Kümmerle, J. McGroddy, D. McQueeney, and P.F. Seidler for their continuous support of the project.

Received: July 25, 2002

[1] R. Goepper, J. Lee-Kalisch, 'Korea: Die alten Königreiche', Kulturstiftung Ruhr Essen (Katalog). Museum Rietberg, Gablerstr. 15, 8002 Zurich, Switzerland, 2000, p. 258

[2] H. Kipphan, 'Handbuch der Printmedien: Technologien und Produktionsverfahren', Springer, Berlin, 2000.

[3] J.M. Adams, D.D. Faux, J.J. Rieber, 'Printing Technology', 4th ed., Delmare Publishers, Albany, NY, 1996.

[4] S. Leppävuori, J. Vaeaenaenen, M. Lahti, J. Remes, A. Uusimaeki, Sensors and Actuators A 1994, 41-42, 593.

[5] M. Lahti, S. Leppävuori, V. Lantto, Appl. Surf. Sci. 1999, 142, 367.

[6] Y. Mikami, Y. Nagae, Y. Mori, K. Kubawara, T. Saito, H. Hayama, H. Asada, Y. Akimoto, M. Kobayashi, S. Okazaki, K. Asaka, H. Matsui, K. Nakamura, E. Kaneko, IEEE Trans. Electron. Dev. 1994, 41, 306.

[7] P.M. Harrey, P.S.A. Evans, B.J. Ramsey, D. Harrison, in 'Proc. 1st Intl. Symp. On Environmentally Conscious Designs and Inverse Manufacturing, Tokyo, Japan, 1999, p. 842.

[8] G. Love, G. Maher, N. Long, in 'Proc. IEEE Intl. Electronic Manufacturing Technology (IEMT)', IEEE, Piscataway, NJ, 1996, p. 167.

[9] H. Gleskova, E.Y. Ma, S. Wagner, D.S. Shen, in '1996 Display Manufacturing Technology Conference. Digest of Technical Papers', 1996, p. 97.

[10] R.H. Detig, in 'Proc. Display Works 99, Manufacturing Technology Conference', San Jose, CA, 1999, p. 97.

[11] R.W. Sabnis, Displays 1999, 20, 119.

[12] E. Cullmann, Semicond. Int. 1985, 8, 332.

[13] H. Huber, U. Scheunemann, E. Cullmann, W. Rohrmoser, Solid State Technol. 1990, 33, 59.

[14] S.K. Ghandi, 'VLSI Fabrication Principles', John Wiley \& Sons, New York, 1983.

[15] G.L.T. Chiu, J.M. Shaw, IBM J. Res Develop. 1997, 41, 3.

[16] A. Kumar, G.M. Whitesides, Appl. Phys. Lett. 1993, 63, 2002.
[17] A. Kumar, N.L. Abbott, E. Kim, H. Biebuyck, G.M. Whitesides, Acc. Chem. Res. 1995, 28, 219.

[18] E. Delamarche, A.C.F. Hoole, B. Michel, S. Wilkes, M. Despont, M.E. Welland, H.A. Biebuyck, J. Phys. Chem. 1997, 101, 9263.

[19] H.A. Biebuyck, N.B. Larsen, E. Delamarche, B. Michel, IBM J. Res. Develop. 1997, 41, 159.

[20] Y. Xia, G.M. Whitesides, Angew. Chem. Int. Ed. 1998, 37, 550.

[21] S. Walheim, R. Muller, M. Sprenger, E. Loser, J. Mlynek, Adv. Mater. 1999, 11, 1431.

[22] N.L. Jeon, I.S. Choni, G.M. Whitesides, N.Y. Kim, P.E. Laibinis, Y. Harada, K.R. Finnie, G.S. Girolami, R.G. Nuzzo, Appl. Phys. Lett. 1999, 75, 4201.

[23] D. Qin, Y. Xia, B. Xu, H. Yang, C. Zhu, G.M. Whitesides, Adv. Mater. 1999, 11, 1433.

[24] [1] R.J. Jackman, S.T. Brittain, A. Adams, H. Wu, M.G. Prentiss, S. Whitesides, G.M. Whitesides, Langmuir 1999, 15, 826.

[25] T. Deng, H.K. Wu, S.T. Brittain, G.M Whitesides, Anal. Chem. 2000, 72, 3176.

[26] R.R. Shah, D. Merreceyes, M. Husemann, I. Rees, N.L. Abbott, C.J. Hawker, J.L. Hedrick, Macromolecules 2000, 33, 597.

[27] W.T.S. Huck, A.D. Strook, G.M. Whitesides, Angew. Chem. Int. Ed. 2000, 39, 1058.

[28] A.J. Black, P.F. Nealey, J.H. Thywissen, M. Deshpande, N. El-Zein, G.N. Maracas, M. Prentiss, G.M. Whitesides, Sensors and Actuators A 2000, 86, 96.

[29] S.Y. Chou, P.R. Krauss, P.J. Renstrom, Appl. Phys. Lett. 1995, 67, 3114.

[30] S.Y. Chou, P.R. Krauss, P.J. Renstrom, Science 1996, 272, 85.

[31] A. Lebib, Y. Chen, J. Bourneix, F. Carcenac, E. Cambril, L. Couraud, H. Launois, Microelectron. Eng. 1999, 46, 319.

[32] A. Lebib, Y. Chen, F. Carcenac, E. Cambril, L. Manin, L. Couraud, H. Launois, Microelectron. Eng. 2000, 53, 175.

[33] H. Schulz, F. Osenberg, J. Engemann, H.C. Scheer, in '16th European Conference on Mask Technology for Integrated Circuits and Microcomponents', Ed. U.F. Behringer, Proc. SPIE 2000, 3996, p. 244.

[34] H. Schift, C. David, M. Gabriel, J. Gobrecht, L.J. Heyderman, W. Kaiser, S. Koeppel, L. Scandella, Microelectron. Eng. 2000, 53, 171.

[35] L. Montelius, B. Heidari, M. Graczyk, T. Ling, I. Maximov, E.L. Sarwe, in 'Emerging Lithographic Technologies IV', Ed. E.A. Dobisz, Proc. SPIE 2000, 3997, 442.

[36] O.J.A. Schueller, S.T. Brittain, G.M. Whitesides, Sensors \& Actuators A 1999, 72, 125.

[37] O.J.A. Schueller, X.M. Zhao, G.M. Whitesides, S. P. Smith, M. Prentiss, Adv. Mater. 1999, 11, 37.

[38] B. Xu, F. Arias, G.M. Whitesides, $A d v$. Mater. 1999, 11, 492.

[39] M.A. Unger, H.P. Chou, T. Thorsen, A. Scherer, S.R. Quake, Science 2000, 288, 113.
[40] C. Bechinger, H. Muffler, C. Schäfle, O. Sundberg, P. Leiderer, Thin Solid Films 2000, 366, 135.

[41] M. Colburn, A. Grot, M. Amistoso, B.J. Cho, T. Bailey, J. Ekerdt, S.V. Sreenivasan, J. Hollenhorst, G.C. Willson, in 'Emerging Lithographic Technologies IV', Ed. E.A. Dobisz, Proc. SPIE 2000, 3997, 453.

[42] A. Bietsch, B. Michel, J. Appl. Phys. 2000, $88,4310$.

[43] H. Schmid, B. Michel, Macromolecules 2000, 33, 3042.

[44] Y. Xia, X.-M. Zhao, G.M. Whitesides, Microelectron. Eng. 1996, 32, 255.

[45] N.B. Larsen, H.A. Biebuyck, E. Delamarche, and B. Michel, J. Am. Chem. Soc. 1997, 119, 3017.

[46] E. Delamarche, H. Schmid, A. Bietsch, N.B. Larsen, H. Rothuizen, B. Michel, H.A. Biebuyck, J. Phys. Chem. B 1998, 102, 3324.

[47] L. Libioulle, A. Bietsch, H. Schmid, B. Michel, E. Delamarche, Langmuir 1999, 15,300 .

[48] J.L. Wilbur, H.A. Biebuyck, J.C. McDonald, G.M. Whitesides, Langmuir 1994, 11, 825.

[49] G.P. Lopez, H.A. Biebuyck, G.M. Whitesides, Langmuir 1993, 9, 1513.

[50] A. Kumar, H.A. Biebuyck, N.L. Abbott, G.M. Whitesides, J. Am. Chem. Soc. 1992 , $114,9188$.

[51] E. Delamarche, B. Michel, H. Biebuyck, C. Gerber, Adv. Mater. 1996, 8, 719.

[52] G. Schmidt, M. Tormen, G. Mueller, L.W. Molenkamp, Y. Chen, A. Lebib, H. Launois, Electron. Lett. 1999, 35, 1731.

[53] Y. Chen, A. Lebib, F. Carcenac, H. Launois, G. Schmidt, M. Tormen, G. Mueller, L.W. Molenkamp, M. Liebau, J. Huskens, S.N. Reinhoudt, Microeletron. Eng. 2000, 53, 253.

[54] E. Delamarche, H. Schmid, B. Michel, H. Biebuyck, Adv. Mater. 1997, 9, 741.

[55] K.L. Johnson, 'Contact Mechanics', Cambridge University Press, Cambridge, England, 1985.

[56] C.D. James, R. Davies, M. Meyer, A. Turner, S. Turner, G. Withers, L. Kam, G. Banker, H. Craighead, M. Isaacson, J. Turner, W. Shain, IEEE Trans. Biomed. Eng. 2000, 47, 17.

[57] A. Folch, M.A. Schmidt, J. Microelectromech. Syst. 1999, 8, 85.

[58] J.A. Rogers, K.E. Paul, G.M. Whitesides, J. Vac. Sci. Technol. B 1998, 16, 88.

[59] T. Burgin, V.-E. Choong, G. Maracas, Langmuir 2000, 16, 5371.

[60] R. Hull, D. Longo, in 'Tenth International Workshop on the Physics of Semiconductor Devices', Eds. V. Kumar, S.K. Agarwal, Proc. SPIE 2000, 3975, p. 974.

[61] A. Bietsch, M.A. Schneider, M.E. Welland, B. Michel, J. Vac. Sci. Technol. B 2000, 18, 1160 .

[62] A. Bietsch, B. Michel, Appl. Phys. Lett. 2002, 80, 3346.

[63] J.F. Bacilek, IS\&T Ann. Conf. 1997, 242.

[64] R.J. Jackman, J. Duffy, E. Ostuni, N.D. Willmore, G.M. Whitesides, Anal. Chem. 1998, 70, 2280. 
[65] E. Kim, Y. Xia, G.M. Whitesides, J. Am. Chem. Soc. 1996, 118, 5722.

[66] E. Delamarche, A. Bernard, H. Schmid, B. Michel, H. Biebuyck, Science 1997, 276, 779.

[67] E. Delamarche, A. Bernard, H. Schmid, A. Bietsch, B. Michel, H. Biebuyck, J. Am. Chem. Soc. 1998, 120, 500.

[68] E. Delamarche, B. Michel, A. Bernard, H. Schmid, E. Haskal, W. Riess, IBM Tech. Disclosure Bull. 2000, 436, 1443.

[69] G.T. Hermanson, A.K. Mallia, P.K. Smith, 'Immobilized Affinity Ligand Techniques', Academic Press, Inc., New York, 1992.

[70] A. Folch, J.B. Ho, O. Hurtado, D.J. Beebe, M. Toner, J. Biomed. Mater. Res. 2000, 52, 346.

[71] B.H. Weigl, P. Yager, Science 1999, 283, 346.

[72] M.U. Kopp, A.J. de Mello, A. Manz, Science 1998, 280, 1046.

[73] A. Bernard, E. Delamarche, H. Schmid, B. Michel, H.R. Bosshard, H. Biebuyck, Langmuir 1998, 14, 2225.

[74] C.D. James, R.C. Davis, L. Kam, H.G. Craighead, M. Isaacson, J.N. Turner, W. Shain, Langmuir 1998, 14, 741.

[75] A. Bernard, J.P. Renault, B. Michel, H.R. Bosshard, E. Delamarche, Adv. Mater. 2000, 12, 1067.

[76] M. Geissler, A. Bernard, A. Bietsch, H. Schmid, B. Michel, E. Delamarche, J. Am. Chem. Soc. 2000, 122, 6303.

[77] G.O. Mallory, J.B. Hajdu, 'Electroless Plating: Fundamentals and Applications', American Electroplaters and Surface Finishers Society, Orlando, FL, 1990.

[78] W.J. Dressick, C.S. Dulcey, J.H. Georger, G.S. Calabrese, J.M. Calvert, J. Electrochem. Soc. 1994, 141, 210.

[79] E.J. O'Sullivan, A.G. Schrott, M. Paunovic, C.J. Sambucetti, J.R. Marino, P.J. Bailey, S. Kaja, K.W. Semkow, IBM J. Res. Develop. 1998, 42, 607.

[80] P.C. Hidber, W. Helbig, E. Kim, G.M. Whitesides, Langmuir 1996, 12, 1375.

[81] H. Kind, M. Geissler, H. Schmid, B. Michel, K. Kern, E. Delamarche, Langmuir 2000, 16, 6367.

[82] H. Schmid, H. Biebuyck, B. Michel, O.J.F. Martin, N. Piller, J. Vac. Sci. Technol. B 1998, 16, 3422.

[83] H. Schmid, H. Biebuyck, B. Michel, O.J.F. Martin, Appl. Phys. Lett. 1998, 72, 2379.

[84] J.A. Rogers, K.E. Paul, R.J. Jackman, G.M. Whitesides, Appl. Phys. Lett. 1997, 70, 2685.

[85] J.A. Rogers, A. Dodabalapur, Z. Bao, H. Katz, Appl. Phys. Lett. 1999, 75, 1010.

[86] Y. Chen, F. Carcenac, C. Ecoffe, D.J. Lougnot, H. Launois, Microelectron. Eng. 1999, 46, 69.

[87] O.J.F. Martin, N.P. Piller, Phys. Rev. E 1998, 58,3909

[88] O.J.F. Martin, N.B. Piller, H. Schmid, H. Biebuyck, B. Michel, Opt. Express 1998, 3, 280.

[89] M. Paulus, B. Michel, O.J.F. Martin, J. Vac. Sci. Technol. B 1999, 17, 3314.

[90] J.G. Goodberlet, B.L. Dunn, Microelectron. Eng. 2000, 53, 95.
[91] R.J. Blaikie, M.M. Alkaisi, S.J. McNab, D.R.S. Cumming, R. Cheung, D.G. Hasko, Microelectron. Eng. 1999, 46, 85.

[92] D.J.D. Carter, H.I. Smith, K.W. Rhee, C. Marrian, in 'Emerging Lithographic Technologies III, Ed. Y. Vladimirsky, Proc. SPIE 1999, 3676, p. 70.

[93] E. Kim, Y. Xia, G.M. Whitesides, Nature 1995, 376, 581

[94] E. Kim, Y. Xia, G.M. Whitesides, J. Am. Chem. Soc. 1996, 118, 5722.

[95] X.M. Zhao, Y. Xia, G.M. Whitesides, $A d v$. Mater. 1996, 8, 837.

[96] H. Kind, J.M. Bonard, C. Emmenegger, L.O. Nilsson, K. Hernadi, E. MaillardSchaller, L. Schlapbach, L. Forro, K. Kern, Adv. Mater. 1999, 11, 1285.

[97] H. Kind, J. M. Bonard, L. Forro, K. Kern, K. Hernadi, L.O. Nilsson, L. Schlapbach, Langmuir 2000, 16, 6877.

[98] A. Cassell, N.R. Franklin, T.W. Tombler, E.M. Chan, J. Han, H. Dai, J. Am. Chem. Soc. 1999, 121, 7975.

[99] S.Y. Chou, L. Zhuang, L. Guo, Appl. Phys. Lett. 1999, 75, 1004.

[100] E. Schäffer, T. Thurn-Albrecht, T.P. Russell, U. Steiner, Nature 2000, 403, 874.

[101] J. Tien, A. Terfort, G.M. Whitesides, Langmuir 1997, 13, 5349.

[102] H.O. Jacobs, G.M. Whitesides, Science 2001, 291, 1763.

[103] S.R. Whaley, S.D. English, E.L. Hu, P.F. Barbara, A.M. Belcher, Nature 2000, 405, 665.

[104] D.E. Ackley, M.J. Heller, C.F. Edman, in 'Proc. LEOS'98, 11th Annual Meeting IEEE Lasers and Electro Optics Society', IEEE, Piscataway, NJ, 1998, p. 85.

[105] N.L. Jeon, J. Hu, G.M. Whitesides, M.K. Erhardt, R.G. Nuzzo, Adv. Mater. 1998, 10, 1466.

[106] J. Hu, R.G. Beck, T. Deng, R.M. Westervelt, K.D. Maranowski, A.C. Gossard, G.M. Whitesides, Appl. Phys. Lett. 1997, 71, 2020.

[107] L.B. Goetting, T. Deng, G.M. Whitesides, Langmuir 1999, 15, 1182.

[108] J. Tate, J.A. Rogers, C.D.W. Jones, B. Vyas, D.W. Murphy, L. Wenjie, B. Zhenans, R. E. Slusher, A. Dodabalapur, H.E. Katz, Langmuir 2000, 16, 6054.

[109] S.T. Brittain, P.J.A. Kenis, O.J.A. Schueller, R.J. Jackman, G.M. Whitesides, Abstr. Papers Am. Chem. Soc. 1998, 216, 43.

[110] W.S. Beh, I.T. Kim, D. Qin, Y. Xia, G.M. Whitesides, Adv. Mater. 1999, 11, 1038.

[111] 'The National Technology Roadmap for Semiconductors', Semiconductor Industry Association, Austin, TX, 1997.

[112] J.M. Xu, Syn. Mater. 2000, 115, 1.

[113] J.A. Rogers, J. Tate, W.J. Li, Z. Bao, A. Dodabalapur, Israel J. Chem. 2000, 40, 139. 